\title{
Steady activity of microfractures on geological faults loaded by mining stress
}

Corresponding author mailing address and e-mail address: M. Naoi, Department of Civil and Earth Resources Engineering, Graduate School of Engineering, Kyoto University, Kyoto

Daigaku Katsura Cluster-C, Nishikyo-ku, Kyoto, 615-8540, Japan, naoi.makoto.4z@kyoto-u.ac.jp. +81-75-383-3211.

Makoto Naoi, Earthquake Research Institute, The University of Tokyo, 1-1-1 Yayoi, Bunkyo-ku, Tokyo, 113-0032, Japan. * Now at Department of Civil and Earth Resources Engineering, Graduate School of Engineering, Kyoto University, Kyoto Daigaku Katsura Cluster-C, Nishikyo-ku, Kyoto, 615-8540, Japan.

Masao Nakatani, Earthquake Research Institute, The University of Tokyo, 1-1-1 Yayoi, Bunkyo-ku, Tokyo, 113-0032, Japan.

Kenshiro Otsuki, Department of Earth Science, Graduate School of Science, Tohoku University, 6-3 Aza-Aoba, Aramaki, Aoba-ku, Sendai, 980-8578, Japan.

Yasuo Yabe, Research Center for Prediction of Earthquakes and Volcanic Eruptions, Graduate School of Science, Tohoku University, 6-6 Aza-Aoba, Aramaki, Aoba-ku, Sendai, 980-8578, Japan.

Thabang Kgarume, Council for Scientific and Industrial Research, PO Box 395, Pretoria, 0001, South Africa.

Osamu Murakami, Research Organization of Science and Engineering, Ritsumeikan University, 1-1-1 Noji Higashi, Kusatsu, 525-8577, Japan.

Thabang Masakale, Open House Management Solutions, P.O. Box 200, Potchefstroom, 2520, South Africa.

Luiz Ribeiro, SeismoGen cc, PO Box 1177, Carletonville, 2500, South Africa.

Anthony Ward, SeismoGen cc, PO Box 1177, Carletonville, 2500, South Africa.

Hirokazu Moriya, Graduate School of Engineering, Tohoku University, 6-3, Aza-Aoba, Aramaki, Aoba-ku, Sendai, 980-8578, Japan. 
Hironori Kawakata, College of Science and Engineering, Ritsumeikan University, 1-1-1 Noji Higashi, Kusatsu, 525-8577, Japan.

Ray Durrheim, The University of the Witwatersrand, 1 Jan Smuts Avenue, Johannesburg, South Africa, and the Council for Scientific and Industrial Research, PO Box 395, Pretoria, South Africa.

Hiroshi Ogasawara, College of Science and Engineering, Ritsumeikan University, 1-1-1 Noji Higashi, Kusatsu, 525-8577, Japan.

Keywords: Acoustic Emission; natural fault; fault core; mining-induced earthquake; seismicity; microfracture 


\section{Abstract}

Acoustic Emissions (AE) down to $M_{W} \sim-4$ were recorded at a site $1 \mathrm{~km}$ beneath the surface in the Cooke 4 Mine, South Africa. Several planar AE clusters with 10-100 m lateral extents were identified. Most of them were located several tens of meters away from the mining front, and exhibited steady activity during the analysis period of about two months. Some of the clusters were consistent with mapped faults. The planar-cluster AEs were sharply aggregated within a thickness of several decimeters, likely delineating the fracture interface of the fault and its higher-order morphology such as branches, bends, and stepovers. The composite focal mechanism evaluated for each cluster was consistent with slip events on the fracture interface. These results imply that numerous shear microfractures occur steadily on a natural fault surface subjected to a stress increase by mining. The planar clusters consist of very small AEs (99.7\% were smaller than $\left.M_{W}-2\right)$, exhibiting high $b$-values much exceeding unity. This contrasts to the more usual $b$-values of the stope-cluster AEs, which were aggregated within $20 \mathrm{~m}$ from the mining front and exhibited a more scattered distribution. Size distribution of microfractures on a fracture interface may directly reflect fine-scale irregularities of the interface. On the other hand, there were many mapped faults not accompanied by AE activities near the planar AE clusters, despite the fact that these quiet faults were subjected to a similar stress history. The presence or absence of AE activities on a fault may reflect different states of the fault, including stress and strength.

\section{Introduction}

The Acoustic Emission (AE) activity preceding a macroscopic shear failure or an unstable slip event has been studied in laboratory experiments as a possible analogue of microseismicity preceding a large earthquake. For example, in a rock fracture experiment using an intact rock, two-dimensional aggregation of AEs to the plane of future through-going rupture is often observed prior to the macroscopic rupture (e.g., Lockner et al., 1991; Lei et al., 2000a-c, 2004). Lei and coauthors reported that such AE activities were more abundant in an experiment on a heterogeneous sample than that on a homogeneous sample (Lei et al., 
2000a-c, 2004) and that their statistical parameters such as $b$-values and fractal dimensions showed characteristic time-dependent patterns precursory to the through-going rupture (e.g., Lei, 2006; Lei and Satoh, 2007). In stick-slip experiments with saw-cut samples, AEs preceding a macroscopic slip event were observed (Thompson et al., 2005). These AEs are often associated with nucleation of a macroscopic slip, which was well investigated by stick-slip experiments (Ohnaka and Shen, 1999). More recently, stick-slip experiments have been conducted on a non-planar fault created by the prior fracturing of an intact rock sample in order to imitate a slip event on a natural fault, which has a more complicated geometrical structure than saw-cut samples (Thompson et al., 2009; Goebel et al., 2012, 2013). In such experiments, AEs that precede a macroscopic event begin to occur at a lower stress level, whereas, similarly to saw-cut sample experiments, their activity increases and the $b$-value decreases with loading.

The knowledge gained from laboratory experiments is expected to be applicable to microseismicity around natural active faults. However, except for aftershocks, microseismicity around faults is not very ubiquitous. Many active faults are not accompanied by steadily occurring microseismicity (Mogi, 1981). It seems surprising that a fault subjected to a stress close to its macroscopic strength is accompanied by little microseismicity. Considering the fractal geometry of natural faults (e.g., Sagy et al., 2007), high-stress spots are likely to be induced easily along a loaded fault, especially at short wavelengths. Numerical simulations by Dieterich and Smith (2009) demonstrated that high-stress spots are distributed ubiquitously along a fault. Hence, it may be natural to imagine that such high-stress spots induce many microfractures close to the central part of the fault, i.e., the "fault core" or "principal slip surface" (PSS), which accommodate most of the shear displacement across the fault zone (Chester and Chester, 1998; Chester et al., 2004).

Nonetheless, there are many active faults accompanied by little microseismicity, as mentioned above. Furthermore, recent studies based on accurate source locations report that microseismic events along a fault, even if they are observed, are actually spread over a broader "damage zone" (Chester et al., 2004) of several hundred meters width around the fault, 
and lack peaks of event density corresponding to the fault core or PSS (Hauksson, 2010; Powers and Jordan, 2010). Repeating earthquakes on plate boundaries (e.g., Nadeau and Johnson, 1998; Matsuzawa et al., 2002) may be the only example of steady activity of on-fault events that has been ever observed.

The reason why on-fault microseismic activity is so rarely observed may simply be that the events are too small to be detected by a conventional seismic network, although other possibilities, such as a large critical size on mature faults (e.g., Dieterich 1986; Marone and Kilgore, 1993), are not excluded. Deep mines, where many earthquakes are induced by the stress concentration produced by excavation, provide a good opportunity to deploy an observation network that can detect very small earthquakes. However, even in observations in mines, there are no published examples of a preexisting fault that was clearly delineated by steady activity of microseismic events, though some studies reported that a larger earthquake $(M>\sim 2)$ reactivated part of a geological fault (e.g., Heesakkers et al., 2011). For example, Snelling et al. (2013) investigated hypocenter distributions of $-2.3 \leq M_{W} \leq 0.8$ events and reported that there was no correlation between the hypocenters and geological faults near the microseismic network. Although some studies examined even smaller events in mines (e.g., Young and Collins, 2001; down to $M_{W}-7$ ), such observations can only detect events in a very limited region because small seismic events radiate high-frequency-dominated waves, which rapidly decay with distance. For instance, the network of Young and Collins (2001) targeted AEs occurring only within several meters from a tunnel, and hence it did not have capability to examine whether AEs occur on a large geological fault or not.

We deployed an AE network (hereinafter referred to as AEnet) $1 \mathrm{~km}$ beneath the surface in the Cooke 4 Mine (previously known as the Ezulwini Mine) in South Africa, which can detect events down to $M_{W}-4$ within $\sim 100 \mathrm{~m}$ around the network (Naoi et al., 2014). From these observations, we found several, thin, planar AE alignments that had a very high event density compared to that in the surrounding region. They consisted of very small AEs; almost all of them were smaller than $M_{W}-2$. Because the AEs aggregated sharply in two dimensions and had composite focal mechanisms that were consistent with slip events on the approximate 
plane of each AE alignment, these AEs are likely to be shear events on pre-existing discontinuities. Indeed, corresponding geological faults were found for some of the alignments. In the present paper, we will describe the features of these AEs.

\section{Observation}

\subsection{Geology and mining around the observation site}

Our observation network (AEnet) was deployed $1 \mathrm{~km}$ beneath the ground, within the 200-m radius circular shaft pillar of the Cooke 4 mine situated in the West Rand gold field near Johannesburg, South Africa. This mine exploits the topmost $10 \mathrm{~m}$ of the Upper Elsburg reef, which contains multiple gold-bearing strata of various thicknesses. The rock around our site, including the reef, is Archaean quartzite of the Witwatersrand supergroup (2.98-2.84Ga), which is overlain by the Ventersdorp supergroup $(2.72-2.63 \mathrm{Ga})$ mainly consisting of lava and in turn the Transvaal supergroup $(2.58-2.20 \mathrm{Ga})$ that continues almost to the ground surface (Dankert and Hein, 2010).

Mining started in 1960. With the exception of the shaft pillar, the Upper Elsburg reef was mined out almost completely by tabular mining, up to 3-m high, by 2001, when the mine was closed. The extensive stopes surrounding the shaft pillar have not been back-filled (installation of bags of tailings to suppress the time-dependent stope closure), so the shaft pillar is subjected to vertical stress that is greater than the virgin stress. Ogasawara et al. (2014) measured in-situ stress in the shaft pillar by the overcoring technique (Sakaguchi et al., 1992; Sugawara and Obara, 1999), and obtained the near-vertical maximum principal stress $\sigma_{1}$ of $127 \mathrm{MPa}$, far greater than the overburden pressure (27 MPa for a depth of $1 \mathrm{~km}$ below the surface).

The mine reopened in 2010 to exploit the Upper Elsburg reef in the shaft pillar. Our study focuses on microseismic events induced by this mining. Fig. 1 shows the mined-out stope around the AEnet for the period July-November 2011, covering the period of the presently used AEnet catalogue. The main shaft is situated at $(x, y)=(-140 \mathrm{~m},-110 \mathrm{~m})$. Tabular mining of $1-2 \mathrm{~m}$ height is advancing along the reef horizon that gently dips $\sim 10^{\circ} \mathrm{WSW}$ in the study 
area. Although the stope in the study area is already quite large, backfill is diligently placed so that true voids are limited to a $\sim 4 \mathrm{~m}$-wide zone behind the mining face. The mining is done by blasting. The face generally advances outward from the center of the shaft pillar towards the rim (i.e., northward in the plotted area of Fig. 1) at a pace of $\sim 10 \mathrm{~m} / \mathrm{month}$.

Many geological faults are known in the shaft pillar from drilling cores and exposures in the mining tunnels. Fault traces (as mapped by December 2013) are shown by brown lines in the plan view of Fig. 1. NNE-trending normal faults, which were formed before the Transvaal age, constitute the dominant fault system in this mine, including outside the shaft pillar. There are also some E-W striking faults, which were formed more recently. Most of the faults in both systems dip steeply at $60^{\circ}-90^{\circ}$. The latest major tectonic event affecting the Witwatersrand Basin was the formation of Karoo Basin at ca. 190-180Ma (Dankert and Hein, 2010). The geological faults have likely been inactive since then. Note that the fault traces shown in Fig. 1 are based only on the mapping at accessible exposures. There is little doubt that there are many unmapped faults in the area, as exemplified in section 3.1. There are also many unmapped joints in the study area that can serve as mechanical discontinuities.

\subsection{AE network and cataloguing procedure}

Our AEnet consists of 6 triaxial accelerometers and 24 higher sensitivity AE sensors, all installed by grouting in boreholes drilled from the tunnel at $1 \mathrm{~km}$ depth (Figs. 1 and 2). Three of the six accelerometers have a flat frequency response up to $25 \mathrm{kHz}$, the three others up to $10 \mathrm{kHz}$. The AE sensors can record signals at workable $\mathrm{S} / \mathrm{N}$ ratios up to about $50 \mathrm{kHz}$ for a majority of events, though this depends on the intensity of the input signal.

In the present paper, we used the AE catalogue of Naoi et al. (2014), which was compiled from $\sim 1.52$ million triggered waveforms $(500 \mathrm{kS} / \mathrm{s} ; 65.5 \mathrm{~ms}$ in length per trigger, including $20 \%$ pretrigger length) obtained during the two months from $6: 32: 22,8$ August 2011 , to 9:54:58, 10 October 2011. Waveforms obtained during periods of heavy data contamination due to working noise (typically 9:00-13:00; see Naoi et al. 2014 for details) were excluded from the analysis. Combined with failure hours of the data logging system, 329 hours were 
regarded as missing data periods. Naoi et al. (2014) applied the automatic picking program of Horiuchi et al. (2011) to them, and extracted 365,237 events that had at least $10 P$ wave travel time readings and root-mean-square arrival-time residuals of $0.2 \mathrm{~ms}$ or less. The average standard errors of these hypocenters are smaller than $1 \mathrm{~m}$ within $50 \mathrm{~m}$ from the center of the AEnet, $\sim 2 \mathrm{~m}$ at $100 \mathrm{~m}$, and $\sim 2.5 \mathrm{~m}$ at $150 \mathrm{~m}$.

Seismic moment $M_{\mathrm{o}}$ and moment magnitude $M_{W}$ were determined for more than $98 \%$ of the 365,237 events, from the spectrum level below the corner frequency. The smallest $M_{W}$ was 5.3. During the analysis period, the detectability of the AEnet was fairly stable because the number of working sensors did not change. The reader is referred to Naoi et al. (2014) for the full account of the network, the recording system, and the catalogue development procedure.

\section{Hypocenter distribution}

\subsection{Overview}

Of the 365,237 AEs, 358,552 are located in the plot area of Fig. 1. Fig. 3 shows them in horizontal projections, each covering a 10-m thickness in the $z$ direction. More than $90 \%$ of them are aggregated in the $20 \mathrm{~m}$-wide zone along the mining front. We refer to this aggregation as the 'stope cluster' (red, thick contour in Fig. 1; see also Naoi et al. 2014). Another minor aggregation can be recognized along the horizontal tunnels (red dashed contours in Fig. 3d). These two aggregations are presumably due to stress concentration around the man-made voids.

On the other hand, several planar AE alignments are recognized away from man-made voids. Blue planes in Fig. 1 represent visually determined approximation planes of relativity large, planar alignments spanning more than $\sim 10 \mathrm{~m}$ (Planes I-VI in Fig. 1). Blue dots in Fig. 3 represent AEs around these planes, which are allocated to the corresponding clusters I-VI in Section 3.2 by using relocated hypocenters and bounding boxes around the planes (Hypocenters in Fig. 3 are shown on the basis of the unrelocated results).

Geological faults likely corresponding to Clusters I and II are known. Cluster I, which dips west, coincides with a part of a large fault running through the AEnet (Zebra fault; the total 
strike extent and offset are several kilometers and several tens of meters at least, respectively). Fig. 2a shows the positions of exposures of this fault that were found by borehole logging and core observation. Exposures of the Zebra fault found in the horizontal tunnels are also shown in Fig. 2b. Fault material observed at these exposures was uncrushed quartz vein up to several decimeters in thickness, hosted in apparently undeformed quartzite (Fig. 2b inset). This implies that the Zebra fault experienced hydrothermal alteration after the fault was formed. As for Cluster II, a fault is exposed on the roof and the sidewall of a tunnel at the position where Cluster II crosses the horizontal tunnel (the dashed line in Fig. 2b). The dip and strike measured for the exposure $\left(\operatorname{dip} \sim 70^{\circ} \mathrm{S}\right.$, strike $\sim \mathrm{N} 105^{\circ} \mathrm{E}$ ) were consistent with the attitude of Plane II. For the exposure, highly sheared material up to several centimeters in thickness was hosted in unreformed rock. We were not able to access the locations of Clusters III-VI, but we think that these clusters also correspond to pre-existing discontinuities such as faults or joints because those AEs sharply concentrate two dimensionally, similarly to Clusters I and II (Section 3.2 and Figs. 7-10).

Most AEs far from man-made voids belong to one of these planar clusters, and AEs outside the two types of clusters mentioned above were few (Figs. 1 and 3). Our AEnet can detect down to $M_{W} \sim-4$ within $100 \mathrm{~m}$ of the center of the network and can detect down to $M_{W}-5$ or less within closer proximity. Even such small events seem to occur only along macroscopic discontinuities or in high-stress regions near voids.

On the other hand, many of the faults shown in Fig. 1 were not accompanied by along-fault AE activities, even if they are situated in the high-detectability region of the AEnet, including the regions closer to the network than the recognized planar clusters. Some of the faults are also situated closer to the mining face than the planar clusters, resulting in larger shear loading by the mining. For example, the faults in the red dashed contour in Fig. 1, which are parts of the E-W striking fault system having $60^{\circ}-90^{\circ}$ in dip (Section 2.1), similar to Planes II-VI, are devoid of any noteworthy activity despite their closer position to the face. Also, many of the N-S striking faults around the similarly oriented Planes I, V and VI are also devoid of AEs. These indicate that the existence of AE activities along a fault does not solely 
depend on the magnitude of shear stress increase. A simplistic interpretation may be that the strength varies greatly from fault to fault.

Yet another type of planar cluster was found near the mining front (Clusters A-C, Figs. 1 and 3f). These clusters, parallel to the mining front, newly emerged after July 2011, and then their activity rate increased significantly. They are probably the result of the increase in differential stress that accompanied the approach of the mining front. Because Clusters $\mathrm{A}-\mathrm{C}$ were documented and discussed in Naoi et al. (submitted), we will not describe them in the present paper. Unlike Clusters A-C, Clusters I-VI are not very close to the mining voids and exhibited steady activities (Section 4.1).

\subsection{Details of planar AE alignments and their allocation to Clusters I-VI}

We made bounding boxes A-D (Fig. 4) containing planar alignments I-VI and relocated AEs in each box by using the double difference technique (Waldhauser and Ellsworth, 2000) as detailed below.

1) AE hypocenters were relocated with the double difference technique by using $d t^{c t}$, travel time differences calculated from the automatic picking results (Section 2.2). For each event, travel time difference $d t^{c t}$ was calculated against events within 10 -m radius, up to 10 strong neighbors (events for which $d t^{c t}$ was ontained for eight phases or more). Initial source locations were given by the results of the automatic picking and location described in Section 2.2 .

2) More accurate travel time differences $d t^{c c}$ were measured using the waveform cross-correlation technique for all event pairs whose inter-event distance was smaller than 4 m. We used filtered $(0.1-20 \mathrm{kHz})$ waveforms of $0.6 \mathrm{~ms}$ in length including $P$ or $S$ wave trains. In order to efficiently select event pairs whose actual hypocenters are close, the pair selection was done on the basis of Step 1 results, not the automatic location results.

3) Hypocenters were relocated again with the double difference algorithm by using $d t^{c c}$ for waveform pairs whose cross correlation coefficient was greater than 0.8 , together with $d t^{c t}$ used in Step 1. The same initial source locations were used as those in Step 1. We labeled the 
analysis as "unsuccessful" whenever the relocated result was $10 \mathrm{~m}$ or more away from its initial location. We initially set the weighting coefficient of $d t^{c t}$ at 100 times greater than that of $d t^{c c}$, and increased the weight of $d t^{c c}$ as the iteration proceeded. The final weight of $d t^{c c}$ is 40 times greater than that of $d t^{c t}$ for the analysis of Box A, C, and D, and 2.5 times greater for the analysis of Box B. We adopted smaller $d t^{c c}$ weight for Box B in order to suppress the artificial separation of hypocenter groups divided by a low AE density part $(x=20 \mathrm{~m}, z=5$ $40 \mathrm{~m}$ in Fig. 6b). When a much greater weighting coefficient for $d t^{c c}$ was tried, $\mathrm{AE}$ hypocenters lying to the east and west of the low-density part kept moving to the east and west, respectively, resulting in an artificial gap around this region. This is probably because the relative location of events separated by the gap was not constrained well due to the small number of $d t^{c c}$ measurements between them. The small final weighting coefficient of $d t^{c c}$ may cause larger relative location errors for AEs in Box B.

The number of events in Box A-D before the relocation was 1205, 10,688, 1237, and 3987, respectively. The number of events successfully relocated in Step 3 was 1118, 10,337, 1156, and 3691, respectively. For each box, the number of $d t^{c t}$ measurements, used in Step 1 and 3, were $94,394,1,027,060,114,656$, and 393,556 for $P$ waves, and 17,900, 306,474, 36,943, and 64,088 for $S$ waves. As for $d t^{c c}$, used in Step 3, the numbers were 65,011, 9,685,818, 259,221, and 3,767,644 for $P$ waves, and 29,689, 999,677, 22,162, and 268,934 for $S$ waves.

The results after Step 3 are shown in Figs. 5-10, each showing all events around planes I-VI, respectively. We used local coordinates which are based on the attitude of planes I'-VI' (not shown), the visually fitted approximation planes for $\mathrm{AE}$ alignments of the relocated hypocenters. The $x$-axis of each local coordinate is taken along the strike direction (parallel to the ground) of the corresponding plane, the $y$-axis is taken along the normal direction, and the $z$-axis is taken along the dip direction. The differences of strike angles between Planes I-VI and Planes I'-VI' were smaller than $5^{\circ}$ and all of the dip angles were the same. The AE hypocenters projected onto $x-y$ planes (Figs. 5a-10a and Figs. 5c-10c) exhibit clear traces continuous over several meters or more, which very likely delineate mechanical discontinuities in the rock. To select the AEs constituting the traces, we made new bounding 
boxes shown by red dashed frames in Figs. 5a-10a and Figs. 5c-10c. In the following analysis, we refer to the groups of AEs in these bounding boxes as Clusters I-VI.

As demonstrated in sliced $x-y$ projections (Figs. 5c-10c), the AEs of each cluster are highly concentrated in very thin zones only several decimeters in thickness. Although location errors of the DD results were not formally evaluated, such thin AE alignments indicate that the relative location errors were smaller than several decimeters. They exhibit high-contrast distributions where event density rapidly decreases outside the narrow zone, which we may call 'trace'. As an example, Fig. 11 shows further details of a part of Cluster VI. Each panel is a $1 \mathrm{~m}$-thick slice of the black frame in the panel for $0 \mathrm{~m} \leq z<5 \mathrm{~m}$ of Fig. 10c. There are 341 AEs in this tiny region, although the number of events in this region may seem to be smaller in Fig. 10 owing to too many overlapping hypocenters. We investigated the distribution of distances from the regression line of the AEs in each slice. As many as $80 \%$ of them are located within only $10 \mathrm{~cm}$ from the lines (the areas shown by the gray zones in Fig. 11), indicating the extreme concentration of AEs onto the central plane of the distribution.

Though the clusters are very tight and two dimensional, they are not necessarily straight, of course. Some curvatures in the strike direction are recognized in Figs. 5c-10c. Also, the sharp, planar traces of AEs in these sliced projections delineate higher-order morphology along the strike. We iterate some examples. 1) We can recognize branches of the AE traces (around $x=$ $0 \mathrm{~m}, y=0 \mathrm{~m}$ of the 3 slices covering $16.5 \mathrm{~m} \leq z<25.5 \mathrm{~m}$ in Fig. 6c). 2) A pair of subparallel traces and partly overlapping traces can be recognized in the enlarged plot of $25.5 \mathrm{~m} \leq z<$ $28.5 \mathrm{~m}$ in Fig. 6c and Fig. 9c $(\mathrm{V}-\mathrm{A}$ and $\mathrm{V}-\mathrm{B})$. They indicate a stepover structure of the discontinuity. 3) Smooth bending can be recognized for all of Clusters I-VI (Fig. 5c-10c). 4) A sharp kink is recognized for Cluster VI (around $x=-5$ of the 2 slices covering $-5 \mathrm{~m} \leq z<5$ $\mathrm{m}$ in Fig. 10c). Such features of the traces, including sharp, thin alignments and their higher-order morphology, can also be recognized in the dip direction. We show just three examples of $y-z$ slices in Fig. 12.

The spatial scale of these higher-order features is similar to that of faults observable on exposures in excavations, and hence it is natural to consider that these sharp AE traces 
correspond to traces of such discontinuities themselves. In the present paper, we use the term 'fracture interface' to refer to the surface of displacement discontinuities in the rock mass that can be recognized at such a scale (exposure scale), including their inclusion such as fault gouges, cataclasite, and fault veins. Although some of the AE traces might represent a joint rather than a fault, we refer to the AEs constituting the traces in Clusters I-VI as 'on-fault' for brevity.

For Cluster VI, subparallel streaks in N-S direction are recognized (Fig. 10b inset). Because they are nearly parallel to the apparent dip of the gold reef, they are likely related to the beddings.

Table 1 shows the number of events in Clusters I-VI, the maximum $M_{W}$ of events belonging to each cluster and the corresponding rupture diameter, and the size and the attitude (strike and dip) of Planes I-VI (based on the results before relocation). The rupture diameter, $r$, was evaluated from the equation

$$
r=2 \times\left(\frac{7}{16} \frac{M o}{\Delta \tau}\right)^{\frac{1}{3}}
$$

(Eshelby, 1957), assuming stress drop $\Delta \tau=3 \mathrm{MPa}$. Of the 12,945 events constituting Clusters I-VI, only 31 events were larger than $M_{W}-2$, and more than $99.7 \%$ were smaller than $M_{W}-2$. Because a fair amount of events are needed to recognize planar aggregation of AEs, it is essentially impossible to notice Clusters I-VI by a conventional seismic network that can detect only large events, say, greater than $M_{W}-2$.

\section{Features of the planar clusters}

\subsection{Long term activity}

The planar clusters exhibit essentially steady activity. That is, their AE rate is generally constant except for a few transient rate-rise events (Fig. 13). Such a steady activity implies that these AEs are driven by steady loading. Remarkable transient rate rises occurred on 21 September 2011 in Cluster II (Fig. 13b) and on 8 and 19 September 2011 in Cluster VI (Fig. 13f). However, AE rate before the first, large transient rate rises (the rate-rise events on 21 
and 8 September 2011 for Clusters II and VI, respectively), all of which occurred in the latter $50 \%$ of the study period, was approximately constant. The rate rise in Cluster II on 21 September 2011 corresponds to aftershock activities induced by $M_{W}-0.1$ and $M_{W} 0.1$ earthquakes, which occurred within 10 minutes at similar locations in the cluster. The rate rises in Cluster VI on 8 and 19 September 2011 likely resulted from blasting because they occurred around 15:00, the typical blasting schedule in this mine. These rate rises were accompanied by aftershock-like rate decay, typically observed for the AE activity following blasting (Naoi et al., 2014).

We contemplate here the possibility that planar clusters I-VI were not an activity induced by steady loading, but were aftershocks of a large earthquake that had a rupture size comparable to the cluster extent (hereinafter referred to as 'mainshock'). A two-dimensional aftershock distribution delineating the rupture area is often observed (e.g., Kato and The Research Team of aftershock observations for the 2004 mid-Niigata Prefecture Earthquake, 2007; Yabe et al., 2009; Naoi et al., 2011), but this is not likely the case for the present data because there are no such large events in Clusters I-VI (Table 1). Even if a mainshock had occurred during a missing data period, then an increase and subsequent decay of AE rate still should have been observed unless the missing data period was fairly long. Such a rate change was not observed except for the cases we have already described above. If a mainshock had occurred during a long missing data period, the rate change following the large event might have been missed completely. However, in the present data, Clusters I-VI were already recognized with the spatial extent shown in Table 1 before the first, relatively long missing data period between 58 September 2011. The planar cluster AEs are, therefore, not aftershocks of a large event that occurred during the analysis period and that ruptured an area comparable to the cluster extent. Although we cannot completely rule out the possibility that such a mainshock occurred before our study period, there is no evidence positively suggesting the occurrence of such a mainshock. 


\subsection{Focal mechanisms}

As shown in Section 3.2, AEs of Clusters I-VI seem to be bound tightly to the fracture interface. If they are slip events on a fracture interface, most of the planar-cluster AEs should have the focal mechanism with a nodal plane consistent with the macroscopic orientation of the interface (e.g., Yabe et al., 2003). To check this expectation, we conducted a composite focal mechanism analysis, plotting polarities of $P$-wave first motions for multiple events constituting each cluster onto a common focal sphere (similar approach to Shearer et al., 2003), by using AE sensor records. If our expectation is correct, the polarity distribution should show a focal mechanism of a slip event on the fracture interface. In the analysis, we used the 30 largest events in each cluster. The $M_{W}$ range of the used events were $-3.7 \leq M_{W} \leq$ -3.1 (Cluster I), $-2.0 \leq M_{W} \leq 0.1$ (Cluster II), $-2.6 \leq M_{W} \leq-1.3$ (Cluster III), $-3.0 \leq M_{W} \leq-$ 2.2 (Cluster IV), $-3.2 \leq M_{W} \leq-2.4$ (Cluster V), and $-2.8 \leq M_{W} \leq-2.1$ (Cluster VI). The number of polarities of $P$-wave first motions for each event was $7-21$ for Cluster I, $10-23$ for

Cluster II, 13-20 for Cluster III, 13-19 for Cluster IV, 15-20 for Cluster V, and 10-22 for Cluster VI. The results are shown in Fig. 1.

The polarities shown in Fig. 1 are not the raw polarities as read from AE sensor records, but are calibrated results so that they represent polarities of ground motions. That is, the red circles in each focal sphere mean that the ground motion of $P$ wave initially moved in the direction away from the source (i.e., compressional wave), and the blue circles mean the opposite direction (i.e., dilatational wave). We estimated the response of AE sensor to the direction of ground motion by comparing the polarity of an AE sensor record (plus or minus) of the $P$-wave first motion to the direction of its ground motion evaluated from the record of a tri-axial accelerometer that was installed close to the AE sensor. We obtained the response for different incident angles by using many events located in various directions from the sensor. This calibration was made by using two pairs of accelerometer and AE sensor with separation distances of $2.0 \mathrm{~m}$ and $3.7 \mathrm{~m}$.

For Cluster I, the obtained polarity distribution suggests the normal slip of rake $90^{\circ}$ on Plane I. Normal slip is reasonable and typical for a shear event induced by mining in South African 
deep gold mines. As for Clusters II-IV and VI, the azimuthal coverage was not good enough to uniquely constrain the focal mechanism, but the obtained distributions are consistent with the normal slip events of rake $90^{\circ}$ on each cluster plane. The result for Cluster $\mathrm{V}$ is consistent with a somewhat oblique normal slip on Plane V. These results imply that most of the AEs constituting each planar cluster are probably normal-slip events on the cluster plane.

\subsection{Size distributions}

We investigated the frequency-magnitude distribution (FMD) of Clusters I-VI and evaluated their $b$-values by using the maximum likelihood method (Aki, 1965; Utsu, 1965). The results are shown in Fig. 14. The minimum validity magnitude, $M_{c}$, of the Gutenberg Richter law (hereinafter referred to as GR law) for each dataset, was evaluated by the Goodness-of-Fit approach (Wiemer and Wyss, 2000; Woessner and Wiemer, 2005). The standard error of $b$-value estimates was calculated after Shi and Bolt (1982). See Appendix D of Naoi et al. (2014) for the detailed description of the $b$-value analysis. As for Clusters II and VI, which experienced large transient rate changes (Section 4.1), we divided the analysis period into 1) the period before the transient rate-rise event, 2) the period from the rate-rise event until the AE rate decays to the approximately same level as that before the event, and 3) after the end of period 2. The $b$-values evaluated for each period are shown alongside the result for all the events in the clusters (Fig. 14b and f). The analysis periods we used are indicated as Period 13 in Fig. 13b and f. As for Cluster VI, the rate-rise event on 8 September 2011 was ignored in the division of the analysis period because the activated period mostly fell in the long missing data period.

AEs in Clusters II-VI follow a power law very well (Fig.14b-f). The rather abrupt deviation from the power law around $M_{c}$, seen in all of them, is probably due to the completeness limit of the catalogue. Their $b$-values vary from cluster to cluster, but all are well constrained as indicated by the small errors $<0.1$. While the cluster-to-cluster variation is certainly there, all these clusters show $b \geq 1.34$, significantly higher than unity, the value typically observed for tectonic seismicity. Especially, if we exclude the periods of large transient rate rise (period 2 
of Cluster II and Cluster VI), $b$-value ranges between 1.38-1.74. In contrast, Naoi et al. (2014) obtained $b \sim 1.2$ for the AEs in the stope cluster (Fig. 1) of the same catalogue, so the tendency of higher $b$-values for these planar clusters is not an artifact due to possible bias in $M_{W}$ estimation but is real. The high $b$-values for the planar clusters, which indicate more extreme extents of the dominance of very small events, are consistent with the fewness of AEs larger than $M_{W}-2$ pointed out earlier (Section 3.2).

As for the other planar cluster, Cluster I (Fig. 14a), all the 851 constituent events were very small $\left(M_{W} \leq-3.1\right.$; Section 3.2 and Table 1), and hence the tendency of the overwhelming dominance of very small events in planar clusters is supported for Cluster I as well. On the other hand, the $b$-value was not well determined. The large error bar in $b$-value estimate for Cluster I resulted from the small number of events larger than the determined $M_{c}$ of -3.5 (only six events). However, this $M_{c}$, the minimum validity magnitude of a power law estimated by the Goodness-of-Fit approach, is not likely to reflect the true completeness magnitude for this cluster's catalogue; it is probably smaller than -3.8 because Cluster I is situated closer to the network than Clusters V and VI, for which $M_{c}=-3.8$ was obtained. By imposing $M_{c}$ of -3.8 to the Cluster I data, we obtain a very high $b$-value of 2.66 with a smaller error of \pm 0.28 , as supported by the steep linear FMD for $M_{W} \geq-3.8$, reflecting marginally sufficient number of events (59) in this range.

\section{Discussion}

As shown in Section 4, the presently studied planar clusters likely consist of slip events on a macroscopic fracture interface. Most of the displacement of geological discontinuities such as faults and joints is accommodated by the fracture interface, and hence the material of the interface is at a singular state in terms of damage. It is, therefore, no wonder that microfractures occur very selectively on the interface. Another interpretation might be possible that the planar-cluster AEs are shear ruptures on small, discrete cracks in the largely intact host rock that are situated within several decimeters from the interface, that is, a narrow damage zone. It is, however, difficult to explain why such small cracks parallel to the 
interface are aggregated only in a very short distance from the interface, so we prefer the former interpretation.

For the two of the six planar clusters, where we could gain access, corresponding geological faults were found, showing that a loaded geological fault can generate on-fault microfractures. As discussed in Section 1, we think the same type microfractures likely occur on an active fault under natural tectonic loading owing to ubiquitous existence of high-stress spots created by the fractal topography of the fault surface (i.e., the PSS or fault core, which corresponds to the fracture interface in this study), though the concentration of such microseismic events to the fault core or PSS has not been recognized for natural seismicity. Even in the cases where microseismicity along a fault is observed, it is claimed that those events are scattered over a significant width comparable to that of the surrounding "damage zone" (Powers and Jordan, 2010), which consists of rocks not accommodating much shear and largely retaining the original texture of the host rock (Chester and Logan, 1986; Chester et al. 2004). Further, it has been pointed out that a narrower peak of event density corresponding to the fault core or PSS is not observed (Hauksson, 2010). However, the lack of large events of $M_{W}>-2$ in the presently observed on-fault AEs, which may result from their high $b$-values, conversely implies that such on-fault microfractures may exist in nature but are merely too small to be detected by conventional seismic observation.

Since most of the slip in large earthquakes occurs within the fault core or even on the PSS (Chester and Chester, 1998; Chester et al., 2004), the on-fault microfractures recognized here represent physical damage in the very material that might eventually rupture as a large earthquake, and may carry direct information about its occurrence. In some cases, it may be even possible that on-fault microfractures are actually the beginning of the rupture of an imminent large earthquake, in other words, constitute a physical precursor (Scholz, 2002). We also note that many of claimed (mainly non-mechanical) short-term precursors can be explained by assuming microfractures (e.g., Scholz, 2002). The present data suggest the possibility that on-fault microfractures are not fictional but only missed by conventional observation, as discussed earlier. The search for on-fault microfractures in natural active faults, 
by deploying much more sensitive seismic networks, may be a worthy challenge.

The main discovery of the present paper is the existence of on-fault microfractures. Furthermore, the narrowness and sharpness of the observed planar AE clusters imply that the damage-zone seismicity, observed around natural active faults (Powers and Jordan, 2010; Hauksson, 2010), is lacking. Especially for the Zebra fault, whose cumulative offset is more than a few tens of meters, the observed decimeter-order thickness of the AE cluster is much less than the expected width of the damage zone, which is about the same as the cumulative offset (Faulkner et al., 2011). The cumulative offset is not known for the faults of the other planar clusters, so we cannot rule out the possibility that they represent seismicity of a 'narrow' damage zone of a fault with small cumulative offsets. However, as we discussed earlier, many features of the planar AE clusters imply that these AEs are on the fracture interface, and therefore are unlikely to be ascribed to a 'narrow damage zone'.

A question here to address is, then, why numerous cracks that must be distributed in the damage zone surrounding the fracture interface remained quiet despite the high stress level sufficient to induce numerous AEs on the fracture interface. One possible explanation may be that small cracks in the damage zone have already healed. This is plausible because the geological faults in the mine have been inactive for a long time, at least since the formation of Karoo Basin at 190-180 Ma (Section 2.1).

The planar clusters observed in this study showed $b$-values considerably higher than unity, the value typically observed for tectonic seismicity, the stope-cluster AEs in the Cooke 4 mine (Naoi et al., 2014), and the whole-mine seismicity (e.g., Boettcher et al., 2009). This latter type of seismicity likely occurs on discrete cracks or faults of various sizes that are three-dimensionally distributed in the largely intact rock volume, whereby the event size distribution is strongly affected by the crack/fault size distribution. In contrast, microfractures on a fracture interface are likely induced by short wavelength heterogeneity in stress and strength created by fine scale irregularities on the interface, i.e. fault topography (Dietrich and Smith, 2009), which, in turn, are likely to affect the size distribution of on-fault events. We propose that on-fault microfractures, which tend to be overwhelmed by very small events to 
an unusual extent, should be regarded as a different population from the population of three-dimensionally distributed earthquakes that tend to follow the GR-law with $b \sim 1$. By investigating the size distribution of on-fault activity, we may obtain information describing the fault topography, which would strongly influence the nucleation of a rupture on the fault (e.g., Ide and Aochi, 2005; Bouchon and Karabulut, 2008; Noda et al., 2013). Indeed, $b$-values differed much among the six planar clusters studied. However, further investigation is needed because probably other factors also affect $b$-values, such as the stress levels (e.g., Scholz, 1968; Schorlemmer et al., 2005; Naoi et al., submitted), and relative orientation between anisotropy of the mechanical characteristics of the rock and the stress field (Lei et al., 2013).

So far, we have discussed planar AE clusters on the basis of the hypothesis that loading to a fault having fractal topography generates many short-wavelength high-stress spots that induce along-fault AEs. We, however, cannot exclude another possibility that those on-fault AEs are ruptures of very small asperities on the fault loaded by a macroscopic fault creep (i.e., AEs as passive frictional noise accompanying a macroscopic stable slip; e.g., Yabe et al., 2003). Actually, repeating earthquakes were identified in Cluster I (Naoi et al., 2013), implying a possible macroscopic creep of the corresponding fault. In addition, the high $b$-values observed for the planar clusters bear resemblance to repeating microearthquakes on the creeping section of the San Andreas Fault (Amelung and King, 1997; Wyss et al., 2004). The streaks of Cluster VI look similar to those observed in the creeping section (Rubin et al., 1999), although the physical relation between streaks and creep has not been understood well. Whether or not macroscopic creep is a necessary condition for steady on-fault seismicity may be answered by monitoring displacement of faults accompanied and not accompanied by AEs, an issue left for future research.

\section{Conclusions}

Our AE observation at $1 \mathrm{~km}$ depth in a South African gold mine revealed AE activities exhibiting clear two-dimensional alignments, or planar clusters, $10-100 \mathrm{~m}$ in lateral extent. 
Most of them were located away from the stope cluster (another AE aggregation that is along the mining face and exhibits a more scattered distribution). Few AEs occur outside the stope or planar clusters. Planar clusters exhibit very sharp distributions with a thickness of only a few decimeters, bound tightly to the central plane of the distribution. The AEs in each cluster even delineate higher-order features such as branches and stepovers. These imply that planar-cluster AEs occurred on the fracture interface. Indeed, corresponding geological faults were found for two clusters that intersect accessible excavations. In addition, a composite focal mechanism analysis for the planar clusters indicated that the AEs in the clusters were slip events on the fracture interfaces. The AE rate of the clusters was generally constant over the two months we analyzed, implying that a loaded geological discontinuity steadily generates numerous microfractures.

On the other hand, some faults were not accompanied by AE activity, though they were located in the region where our AE network could detect AEs down to $M_{W}-4$ if they occurred. A simplistic interpretation may be that on-fault AEs are generated only on a fault where the stress on the fault is high enough, not much below the strength. Another possibility is that the occurrence of a macroscopic creep was the key for on-fault AE activity, but concurrent displacement measurements are necessary to explore this.

The AEs constituting the planar clusters were very small, $99.7 \%$ or more being smaller than $M_{W}-2$. They exhibit $b$-values considerably higher than unity, the value representative for both natural and mine seismicity. The size distribution of on-fault microseismicity may reflect the topography of the macroscopically two-dimensional fracture interface, while the size distribution of seismicity that distributed three-dimensionally may reflect the size distribution of cracks/faults over the volume. From this viewpoint, we propose that 'on-fault microfractures' should be regarded as a different population from the 'earthquakes'.

Previous studies for natural active faults did not find microfractures bound to the fracture interface such as the PSS or the fault core, which is the site of most slip displacement in large earthquakes. However, considering that the AEs in the planar clusters we found were extremely dominated by very small events of $M_{W}<-2$, we propose that very small seismic 
events (or microfractures), undetectable by the conventional seismic network, may actually occur on active faults, because many active faults should be subjected to the stress not much below the strength.

\section{Acknowledgments}

We thank Gold One International Ltd., operator of the Cooke 4 mine, for approving our publication, and personnel at the mine and at the Institute of Mine Seismology for facilitating our project. We dedicate this paper to late Gilbert Morema, who was the real engine of the AE observation. We also thank Christopher H. Scholz and an anonymous reviewer for comments that helped to improve the manuscript. This project was funded by Grants-in-Aid from the Ministry of Education, Culture, Sports, Science and Technology (MEXT) of Japan (21224012, 21246134, 26249137, 26887022). It was also funded by JST/JICA, SATREPS, and the MEXT's Earthquake and Volcano Hazards Observation and Research Program. RJD acknowledges support from the South African Research Chairs Initiative of the Department of Science and Technology and the National Research Foundation. 


\section{References}

Aki, K., 1965. Maximum likelihood estimate of $b$ in the formula $\log N=a-b M$ and its confidence limits, Bull. Earthq. Res. Inst. Univ. Tokyo, 43, 237-239.

Amelung, F., and G. C. P. King, 1997. Earthquake scaling laws for creeping and non-creeping faults, Geophys. Res. Lett., 24, 507-510m, doi: 10.1029/97GL00287.

Boettcher, M. S., A. McGarr, and M. Johnston, 2009. Extension of Gutenberg-Richter distribution to $M_{W}-1.3$, no lower limit in sight, Geophys. Res. Lett. 36, L10307, doi:10.1029/2009GL038080.

Bouchon, M., and H. Karabulut, 2008. The aftershock signature of supershear earthquakes, Science 320, 1323, doi: 10.1126/science.1155030.

Chester, F. M., and J. S. Chester ,1998. Ultracataclasite structure and friction processes of the Punchbowl fault, San Andreas system, California, Tectonophysics 295, 199-221, doi:10.1016/S0040-1951(98)00121-8.

Chester, F. M., J. S. Chester, D. L. Kirschner, S. E. Schulz, and J. P. Evans, 2004. Structure of large-displacement, strike-slip fault zones in the brittle crust, in Rheology and Deformation in the Lithosphere at Continental Margins, edited by G. D. Karner et al., pp. 223-260, Columbia Univ. Press, New York.

Chester, F. M., J. M. Logan, 1986. Implications for mechanical properties of brittle faults from observations of the Punchbowl fault zone, California, Pure Appl. Geophys, 124, 79104.

Dankert, B. T., and K. Hein, 2010. Evaluating the structural character and tectonic history of the Witwatersrand Basin, Precambrian Research 177, 1-22, doi:10.1016/j.precamres.2009.10.007.

Dieterich, J. H., A model for the nucleation of earthquake slip, In Earthquake Source Mechanics, Geophys. Monogr. Ser., vol. 37, (ed. Das, S., J. Boatwright, and C. H. Scholz), American Geophysical Union, 1986, pp. 37-47.

Dieterich, J. H., and D. E. Smith, 2009. Nonplanar faults: mechanics of slip and off-fault damage, Pure Appl. Geophys. 166, 1799-1815, doi:10.1007/978-3-0346-0138-2_12. 
Eshelby, J. D., 1957. The determination of the elastic field of an ellipsoidal inclusion, and related problems, Proc. Roy. Soc. London A 241, 376-396.

Faulkner, D. R., T. M. Mitchell, E. Jensen, and J. Cembrano, 2011. Scaling of fault damage zones with displacement and the implications for fault growth processes, J. Geophys. Res. 116, B05403, doi:10.1029/2010JB007788.

Goebel, T. H. W., T. W. Becker, D. Schorlemmer, S. Stanchits, C. Sammis, E. Rybacki, and G. Dresen, 2012. Identifying fault heterogeneity through mapping spatial anomalies in acoustic emission statistics, J. Geophys. Res. 117, B03310, 1978-2012, doi:10.1029/2011JB008763.

Goebel, T. H. W., D. Schorlemmer, T. W. Becker, G. Dresen, and C. G. Sammis, 2013. Acoustic emissions document stress changes over many seismic cycles in stick-slip experiments, Geophys. Res. Lett. 40, 2049-2054, doi:10.1002/grl.50507.

Hauksson, E., 2010. Spatial separation of large earthquakes, aftershocks, and background seismicity: Analysis of interseismic and coseismic seismicity patterns in southern California, Pure Appl. Geophys. 167, 979-997, doi:10.1007/s00024-010-0083-3.

Heesakkers, V., S. Murphy, and Z. Reches, 2011. Earthquake rupture at focal depth, Part I: Structure and rupture of the Pretorius Fault, TauTona Mine, South Africa, Pure Appl. Geophys. 168, 2395-2425, doi:10.1007/s00024-011-0354-7.

Horiuchi, S., Y. Horiuchi, Y. Iio, Y. Sawada, S. Sekine, H. Nakamura, T. Okada, M. Nakatani, and M. Naoi, 2011. Automatic $P$ and $S$ wave arrival time picking compared to manually picking, IUGG General Assembly, 3430, Melbourne, Australia.

Ide, S., and H. Aochi, 2005. Earthquakes as multiscale dynamic ruptures with heterogeneous fracture surface energy, J. Geophys. Res. 110, B11303, doi:10.1029/2004JB003591. Kato, A., The Research Team of aftershock observations for the 2004 mid-Niigata Prefecture Earthquake, 2007. High-resolution aftershock observations in the source region of the 2004 mid-Niigata Prefecture Earthquake, Earth Planets Space 59, 923-928.

Lei, X., 2006. Typical phases of pre-failure damage in granitic rocks under differential compression, in Fractal Analysis for Natural Hazards, G. Cello, and B. D. Malamud 
(Editors), Geological Society, London, Special Publication 261, 11-29, doi:

10.1144/GSL.SP.2006.261.01.02.

Lei, X., and T. Satoh, 2007. Indicators of critical point behavior prior to rock failure inferred from pre-failure damage, Tectonophysics 431, 97-111, doi:10.1016/j.tecto.2006.04.023.

Lei, X., K. Kusunose, M. V. M. S. Rao, O. Nishizawa, and T. Satoh, 2000a. Quasi-static fault growth and cracking in homogeneous brittle rock under triaxial compression using acoustic emission monitoring, J. Geophys. Res. 105, 6127-6139, doi:10.1029/1999JB900385.

Lei, X.-L., K. Kusunose, O. Nishizawa, A. Cho, and T. Satoh, 2000b. On the spatio-temporal distribution of acoustic emissions in two granitic rocks under triaxial compression: The role of pre-existing cracks, Geophys. Res. Lett. 27, 1997-2000, doi:10.1029/1999GL011190 .

Lei, X.-L., O. Nishizawa, K. Kusunose, A. Cho, T. Satoh and O. Nishizawa, 2000c. Compressive failure of mudstone samples containing quartz veins using rapid $\mathrm{AE}$ monitoring: The role of asperities, Tectonophysics 328, 329-340, doi:10.1016/S0040-1951(00)00215-8.

Lei, X., K. Masuda, O. Nishizawa, L. Jouniaux, L. Liu, W. Ma, T. Satoh, and K. Kusunose, 2004. Detailed analysis of acoustic emission activity during catastrophic fracture of faults in rock, J. Struct. Geol. 26, 247-258, doi:10.1016/S0191-8141(03)00095-6.

Lei, X., T. Funatsu, and E. Villaescusa, 2013. Fault formation in foliated rock -insights gained from a laboratory study, In Proc 8th Int Symp on Rockbursts and Seismicity in Mines (RaSim8) (ed. Malovichko A, Malovichko D), Russia Saint-Peterburg-Moscow, 41-49.

Lockner, D. A., J. D. Byerlee, V. Kuksenko, A. Ponomarev, and A. Sidorin, 1991. Quasi-static fault growth and shear fracture energy in granite, Nature 350, 39-42, doi: $10.1038 / 350039 \mathrm{a} 0$.

Marone, C., and Kilgore, B., 1993. Scaling of the critical slip distance for seismic faulting with shear strain in fault zones. Nature 362, 618-621, doi: 10.1038/362618a0. 
Matsuzawa, T., T. Igarashi, and A. Hasegawa, 2002. Characteristic small-earthquake sequence off Sanriku, northeastern Honshu, Japan, Geophys. Res. Lett., 29, 1543, doi:10.1029/2001GL014632.

Mogi, K., 1981. Earthquake prediction program in Japan, Maurice Ewing Ser. 4, 635-666, doi:10.1029/ME004p0635.

Nadeau, R. M., and L. R. Johnson, 1998. Seismological studies at Parkfield VI: Moment release rates and estimates of source parameters for small repeating earthquakes, Bull. Seismol. Soc. Am. 88, 790-814.

Naoi, M., M. Nakatani, Y. Yabe, G. Kwiatek, T. Igarashi, and K. Plenkers, 2011. Twenty thousand aftershocks of a very small (M 2) earthquake and their relation to the mainshock rupture and geological structures, Bull. Seismol. Soc. Am. 101, 2399-2407, doi:10.1785/0120100346.

Naoi, M., M. Nakatani, K. Otsuki, T. Kgarume, J. Philipp, T. Masakale, L. Ribeiro, H. Moriya, O. Murakami, Y. Yabe, H. Kawakata, A. Ward, R. Durrheim, H. Ogasawara, 2013. Small Repeating Earthquakes of $-5.1 \leq M_{W} \leq-3.6$ on a Fault Loaded by Mining in a South African Gold Mine (in Japanese), Abs. Seismol. Soc. Japan 2013 Fall Meeting, A11-09.

Naoi, M., M. Nakatani, S. Horiuchi, Y. Yabe, J. Philipp, T. Kgarume, G. Morema, S. Khambule, T. Masakale, L. Ribeiro, K. Miyakawa, A. Watanabe, K. Otsuki, H. Moriya, O. Murakami, H. Kawakata, N. Yoshimitsu, A. Ward, R. Durrheim, H. Ogasawara, 2014. Frequency-magnitude distribution of $-3.7 \leq M_{W} \leq 1$ mining-induced earthquakes around a mining front and $b$-value invariance with post-blast time, Pure Appl. Geophys., 171, 2665-2684, doi: 10.1007/s00024-013-0721-7.

Naoi, M., M. Nakatani,T. Kgarume, S. Khambule, T. Masakale, L. Ribeiro, J, Philipp, S. Horiuchi, K. Otsuki, K. Miyakawa, A. Watanabe, H. Moriya, O. Murakami, Y. Yabe, H. Kawakata, N. Yoshimitsu, A. Ward, R. Durrheim, H. Ogasawara, Quasi-static slip patch growth to $20 \mathrm{~m}$ on a geological fault inferred from acoustic emissions in a South African gold mine, J. Geophys. Res. submitted. 
Noda, H., M. Nakatani, and T. Hori, 2013. Large nucleation before large earthquakes is sometimes skipped due to cascade-up -Implications from a rate and state simulation of faults with hierarchical asperities, J. Geophys. Res. 118, 2924-2952, doi:10.1002/jgrb.50211.

Ogasawara H., H. Kato, G. Hofmann, D. Roberts, P. Piper, T. Clements, A. K. Ward, Y. Yabe, H. Yilmaz, R. J. Durrheim, 2014. BX CCBO in-situ stress measurements at earthquake prone areas in South African gold mines -a summary of mini-workshop on 13 Feb 2014, In Proceedings of 48th US Rock Mechanics/Geomechanics Symposium, 14-7438, Minneapolis.

Ohnaka, M., and L. Shen, 1999. Scaling of the shear rupture process from nucleation to dynamic propagation: Implications of geometric irregularity of the rupturing surfaces, J. Geophys. Res. 104, 817-844, doi: 10.1029/1998JB900007.

Powers, P. M., and T. H. Jordan, 2010. Distribution of seismicity across strike-slip faults in California, J. Geophys. Res. 115, B05305, doi:10.1029/2008JB006234.

Rubin, A. M., D. Gillard, and J. L. Got, 1999. Streaks of microearthquakes along creeping faults, Nature, 400(6745), 635-641, doi:10.1038/23196.

Sagy, A., E. E. Brodsky, and G. J. Axen, 2007. Evolution of fault-surface roughness with slip, Geology 35, 283-286, doi:10.1130/G23235A.1.

Sakaguchi, K., Y. Obara, T. Nakayama, and K. Sugawara, 1992. Accuracy of rock stress measurement by means of conical-ended borehole technique, J. Min. Material Process. Inst., 108: 455-460.

Scholz, C. H., 1968. The frequency-magnitude relation of microfracturing in rock and its relation to earthquakes, Bull. Seismol. Soc. Am. 58, 399-415.

Scholz, C. H., 2002. The Mechanics of Earthquakes and Faulting, 2nd ed., Cambridge Univ. Press, Cambridge, U. K.

Schorlemmer, D., S. Wiemer, and M. Wyss, 2005. Variations in earthquake-size distribution across different stress regimes, Nature 437, 539-542, doi: 10.1038/Nature04094. 
Shearer, P. M., J. L. Hardebeck, L. Astiz, and K. B. Richards-Dinger, 2003. Analysis of similar event clusters in aftershocks of the 1994 Northridge, California, earthquake, J. Geophys. Res. 108, 2035, doi:10.1029/2001JB000685.

Shi, Y., and B. A. Bolt, 1982. The standard error of the magnitude-frequency $b$ value, Bull. Seismol. Soc. Am. 72, 1677-1687.

Snelling, P. E., L. Godin, and S. D. McKinnon, 2013. The role of geologic structure and stress in triggering remote seismicity in Creighton Mine, Sudbury, Canada, Int. J. Rock Mech. Min. Sci. 58, 166-179, doi:10.1016/j.ijrmms.2012.10.005.

Sugawara, K., and Y. Obara, 1999. Draft ISRM suggested method for in situ stress measurement using the compact conical-ended borehole overcoring (CCBO) technique, Int. J. Rock Mech. Min. Sci. 36, 307-322.

Thompson, B. D., R. P. Young, and D. A. Lockner, 2005. Observations of premonitory acoustic emission and slip nucleation during a stick slip experiment in smooth faulted Westerly granite, Geophys. Res. Lett. 32, L10304, doi:10.1029/ 2005GL022750.

Thompson, B. D., R. P. Young, and D. A. Lockner, 2009. Premonitory acoustic emissions and stick-slip in natural and smooth-faulted Westerly granite, J. Geophys. Res. 114, doi:10.1029/2008JB005753.

Utsu, T., 1965. A method for determining the value of $b$ in a formula $\log n=a-b \mathrm{M}$ showing the magnitude-frequency relation for earthquakes (in Japanese with English abstract), Geophys. Bull. Hokkaido Univ. 13, 99-103.

Waldhauser, F., and W. L. Ellsworth, 2000. A double-difference earthquake location algorithm: Method and application to the northern Hayward fault, California, Bull. Seismol. Soc. Am. 90, 1353-1368, doi: 10.1785/0120000006.

Wiemer, S., and M. Wyss, 2000. Minimum magnitude of completeness in earthquake catalogs: Examples from Alaska, the western United States, and Japan, Bull. Seismol. Soc. Am. 90, 859-869, doi:10.1785/0119990114. 
Woessner, J., and S. Wiemer, 2005. Assessing the quality of earthquake catalogues:

Estimating the magnitude of completeness and its uncertainty, Bull. Seismol. Soc. Am. 95, 684-698, doi: 10.1785/0120040007.

Wyss, M., C. G. Sammis, R. M. Nadeau, and S. Wiemer, 2004. Fractal dimension and b-value on creeping and locked patches of the San Andreas fault near Parkfield, California, Bulletin of the Seismological Society of America, 94(2), 410-421, doi:

$10.1785 / 0120030054$.

Yabe, Y., N. Kato, K. Yamamoto, and T. Hirasawa, 2003. Effect of sliding rate on the activity of acoustic emission during stable sliding, Pure Appl. Geophys. 160, 1163-1189.

Yabe, Y., J. Philipp, M. Nakatani, G. Morema, M. Naoi, H. Kawakata, T. Igarashi, G. Dresen, H. Ogasawara, and JAGUARS, 2009. Observation of numerous aftershocks of an $M_{W} 1.9$ earthquake with an AE network installed in a deep gold mine in South Africa. Earth Planets Space 61, e49-e52.

Young, R. P., and D. S. Collins, 2001. Seismic studies of rock fracture at the Underground Research Laboratory, Canada, Int. J. Rock Mech. Min. Sci. 38, 787-799, doi:10.1016/S1365-1609(01)00043-0. 
Fig. 1. Hypocenter distribution of 358,552 AEs (gray dots) around our AE network (Fig. 2). The origin in the $x-y$ plane corresponds to the center of the AE network, and the origin in the $z$-coordinate corresponds to the level of the horizontal tunnel (gray lines) at $1 \mathrm{~km}$ depth. Blue planes with bold black top edges: approximation planes visually fitted for planar $\mathrm{AE}$ alignments (Plane VI corresponds to Plane E in Naoi et al., submitted). Red, green, magenta, and cyan hatches: mined-out stopes. Brown lines: fault traces at the stope level mapped by the mine. Focal spheres in lower hemisphere projection are shown with the $P$-wave first motion polarities for the 30 largest events in each cluster. The red circles in each focal sphere mean that the ground motion of $P$ wave initially moved in the direction away from the source (i.e., compressional wave), and the blue circles mean the opposite direction (i.e., dilatational wave). The nodal plane in each focal sphere corresponds to a normal slip on each plane (The rake angle is $-90^{\circ}$ for Clusters I-IV and VI, $-130^{\circ}$ for Cluster V).

Fig. 2. AE array configuration and the position of the Zebra fault. The coordinate system is the same as that of Fig. 1. a) Positions of sensors and the Zebra fault. Magenta diamonds denote the intersections between the fault and the boreholes, confirmed by borehole logging and core observation. Blue plane: the approximation plane of the planar AE alignment along the fault (same as Plane I in Fig 1). b) Positions of fault exposures at horizontal tunnels. Solid thick lines: Positions of the exposures of the Zebra fault. Dashed line: Position of the fault exposure corresponding to Cluster II. Different colors denote exposures at different elevations (the horizontal tunnels are shown only for $1 \mathrm{~km}$ depth for visibility). Angle of the solid and dashed lines corresponds to strike of the faults measured at each exposure. Blue frame: the plot area of a). Inset photo: an example of exposure of the Zebra fault.

Fig. 3. AE hypocenters projected onto the $x-y$ plane, each covering a $10-\mathrm{m}$ thickness in the $z$ direction. The coordinate system is the same as that of Figs. 1 and 2, and the plotted events are the same as those shown in Fig. 1. The horizontal tunnel at $1 \mathrm{~km}$ depth and the mined out area are shown for reference in all horizontal slices. Blue dots: AEs belonging to Clusters I- 
VI defined in Section 3.2. Gray dots: otherwise.

Fig. 4. Boxes A-D used in the event selection for the double difference relocation.

Fig. 5. Maps of the relocated AEs situated within $10 \mathrm{~m}$ of Plane I', which is a visually fitted plane based on the relative relocation results. A local coordinate system aligned with Plane I' is used: $x$, along strike (positive southward), $y$, normal to the plane (positive eastward), and $z$, along dip (positive upward). a) Projection onto the $x-y$ plane. b) Projection onto the $x-z$ plane. c) Projections onto the $x-y$ plane, each covering a $10-\mathrm{m}$ thickness in the $z$ direction. Blue dots are AEs defined as Cluster I, which are situated in the red dashed frames in a) and c). Gray dots are other events.

Fig. 6. Maps of the relocated AEs situated within $10 \mathrm{~m}$ of Plane II', a visually fitted plane based on the relative relocation results. A local coordinate system aligned with Plane II' is used: $x$, along strike (positive eastward), $y$, normal to the plane (positive northward), and $z$, along dip (positive upward). a) Projection onto the $x-y$ plane. b) Projection onto the $x-z$ plane. c) Examples of projections onto the $x-y$ plane for $13.5 \mathrm{~m} \leq z<34.5 \mathrm{~m}$, each covering a 3-m thickness in the $z$ direction. Blue dots are AEs defined as Cluster II, which are situated in the red dashed frames in a) and c). Gray dots are other events. The events located at $x \geq 30 \mathrm{~m}$ are excluded from Cluster II and are defined as Cluster III or IV.

Fig. 7. Maps of the relocated AEs situated within $5 \mathrm{~m}$ of Plane III', a visually fitted plane based on the relative relocation results. A local coordinate system aligned with Plane III' is used: $x$, along strike (positive eastward), $y$, normal to the plane (positive northward), and $z$, along dip (positive upward). a) Projection onto the $x-y$ plane. b) Projection onto the $x-z$ plane. c) Projections onto the $x-y$ plane, each covering a 5-m thickness in the $z$ direction. Blue dots are AEs defined as Cluster III, which are situated in the red dashed frames in a) and c). Gray dots are other events. 
Fig. 8. Maps of the relocated AEs situated within $3 \mathrm{~m}$ of Plane IV', a visually fitted plane based on the relative relocation results. A local coordinate system aligned with Plane IV' is used: $x$, along strike (positive eastward), $y$, normal to the plane (positive northward), and $z$, along dip (positive upward). a) Projection onto the $x-y$ plane. b) Projection onto the $x-z$ plane. c) Projections onto the $x-y$ plane, each covering a 2-m thickness in the $z$ direction. Blue dots are AEs defined as Cluster IV, which are situated in the red dashed frames in a) and c). Gray dots are other events.

Fig. 9. Maps of the relocated AEs situated within $6 \mathrm{~m}$ of Plane $\mathrm{V}^{\prime}$, a visually fitted plane based on the relative relocation results. A local coordinate system aligned with Plane $\mathrm{V}^{\prime}$ is used: $x$, along strike (positive southward), $y$, normal to the plane (positive eastward), and $z$, along dip (positive upward). a) Projection onto the $x-y$ plane. b) Projection onto the $x-z$ plane. c) Projections onto the $x-y$ plane, each covering a 5-m thickness in the $z$ direction. Blue dots are AEs defined as Cluster V, which are situated in the red dashed frames in a) and c). Gray dots are other events. A stepover structure (the offset between alignments V-A and V-B) is recognized.

Fig. 10. Maps of the relocated AEs situated within $5 \mathrm{~m}$ of Plane VI', a visually fitted plane based on the relative relocation results. A local coordinate system aligned with Plane VI' is used: $x$, along strike (positive northward), $y$, normal to the plane (positive westward), and $z$, along dip (positive upward). a) Projection onto the $x-y$ plane. b) Projection onto the $x-z$ plane. Inset: subparallel streaks in N-S direction (Gray lines). c) Projections onto the $x-y$ plane, each covering a 5-m thickness in the $z$ direction. Blue dots are AEs defined as Cluster VI, which are situated in the red dashed frames in a) and c). Gray dots are other events. The black frame in the panel for $0 \mathrm{~m} \leq z<5 \mathrm{~m}$ corresponds to the plot area of Fig. 11. 
Fig. 11. Detailed distribution of 341 AEs in the black frame in the $0 \mathrm{~m} \leq z<5 \mathrm{~m}$ panel of Fig. 10c. Each panel shows a projection onto the $x-y$ plane covering a $1-\mathrm{m}$ thickness in the $z$ direction. Gray zones show the area within $10 \mathrm{~cm}$ from the regression line estimated for the hypocenters in each panel.

Fig. 12. Examples of $y-z$ projections for Clusters I, II and V. a) Cluster I. b) Cluster II. c) Cluster V. The local coordinates used in Figs. 5, 6 and 9 were used. Each slice covers the same thicknesses used in Figs. 5c, 6c and 9c, respectively.

Fig. 13. Cumulative number of the AEs in Cluster I-VI, and their magnitude-time diagrams. The gray stripes indicate missing data periods. The broken lines in b) and f) are for partitioning periods for the $b$-value analysis (Fig. 14). The broken lines in b) indicate the timing of 6:50.22.671 on 21 September 2011 (The occurrence time of $M_{W} 0.1$ on Cluster II) and of 0:0:0 on 28 September 2011. The broken lines in $\mathrm{f}$ ) indicate the timing of 15:18.07.265 on 19 September 2011, when the AE rate in Cluster VI increased rapidly, and 0:0:0 on 28 September 2011 .

Fig. 14. Frequency-magnitude distribution and $b$-values of Clusters I-VI. As for Cluster II (b) and VI (f), which experienced large transient rate changes (Section 4.1), the results are shown for each of the periods 1-3 (see text) alongside the result for all the events in the clusters. Red, green, and blue symbols correspond to Period 1-3, respectively. The standard error of $b$-values was estimated after Shi and Bolt (1982). 
Table 1. Information of planar AE clusters

\begin{tabular}{cccccc}
\hline $\begin{array}{c}\text { Cluster } \\
\text { No. }\end{array}$ & $\begin{array}{c}\text { Number } \\
\text { of events }\end{array}$ & $\left.\begin{array}{c}\text { Max. } M_{W} \\
(\text { corresponding } \\
\text { rupture diameter }\end{array}{ }^{1}, \mathrm{~m}\right)$ & $\begin{array}{c}\text { Cluster size, } \mathrm{m}^{2} \\
(\text { size of planes in Fig. }\end{array}$ & Strike & Dip \\
\hline I & 851 & $-3.1(0.64)$ & $93 \times 65$ & $\mathrm{~N} 186^{\circ} \mathrm{E}$ & $57^{\circ} \mathrm{W}$ \\
II & 7125 & $0.1(25.5)$ & $67 \times 80$ & $\mathrm{~N} 108^{\circ} \mathrm{E}$ & $78^{\circ} \mathrm{S}$ \\
III & 1143 & $-1.3(5.09)$ & $28 \times 18$ & $\mathrm{~N} 75^{\circ} \mathrm{E}$ & $72^{\circ} \mathrm{S}$ \\
IV & 355 & $-2.2(1.81)$ & $19 \times 13$ & $\mathrm{~N}^{\circ} \mathrm{E}$ & $68^{\circ} \mathrm{S}$ \\
V & 866 & $-2.4(1.43)$ & $36 \times 38$ & $\mathrm{~N} 196^{\circ} \mathrm{E}$ & $66^{\circ} \mathrm{W}$ \\
VI & 2605 & $-2.1(2.03)$ & $26 \times 30$ & $\mathrm{~N}^{\circ} 38^{\circ} \mathrm{E}$ & $71^{\circ} \mathrm{E}$ \\
\hline
\end{tabular}

1. Rupture diameters are calculated from formula in Eshellby (1957) assuming $3 \mathrm{MPa}$ of stress drop. 


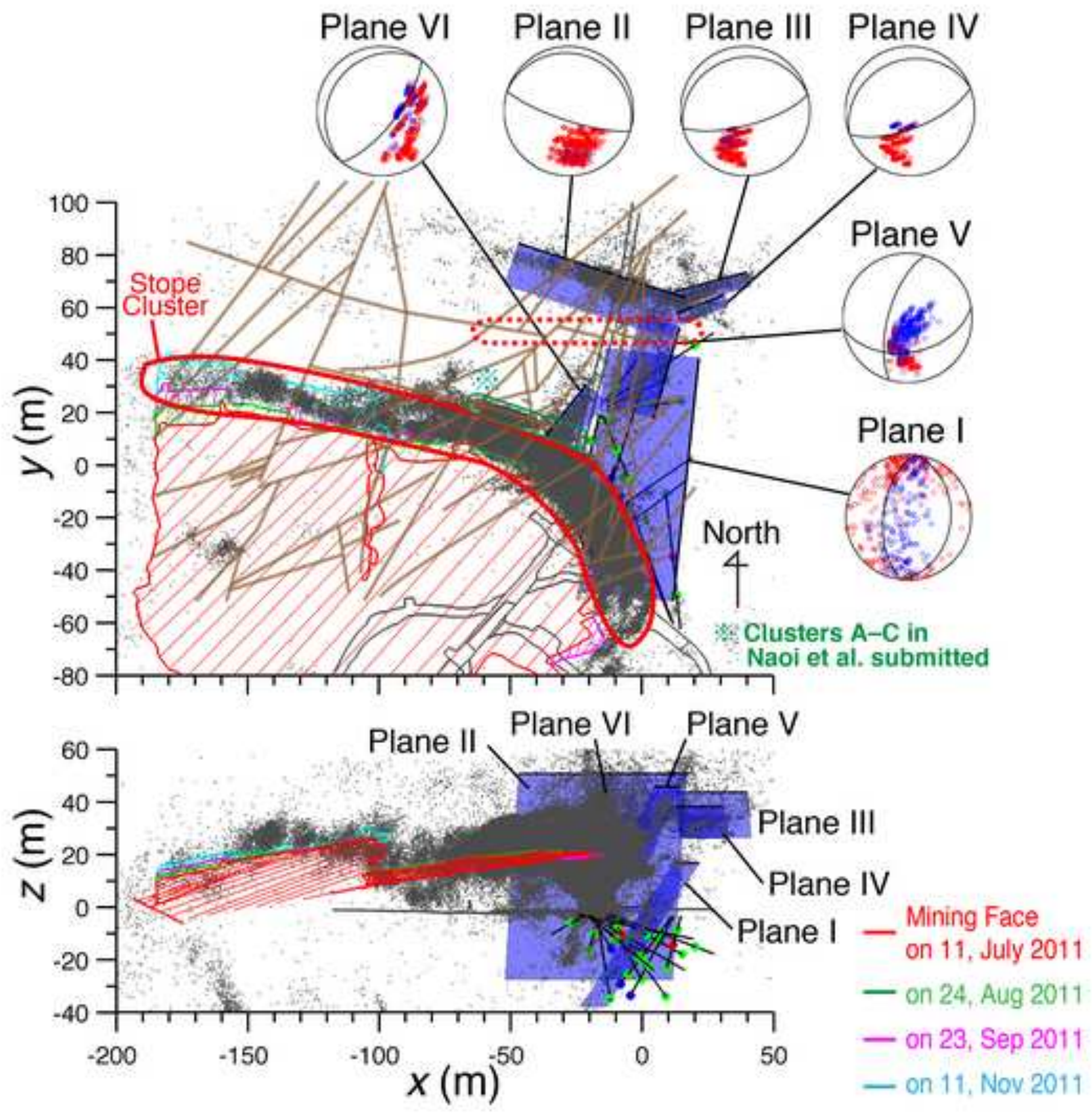




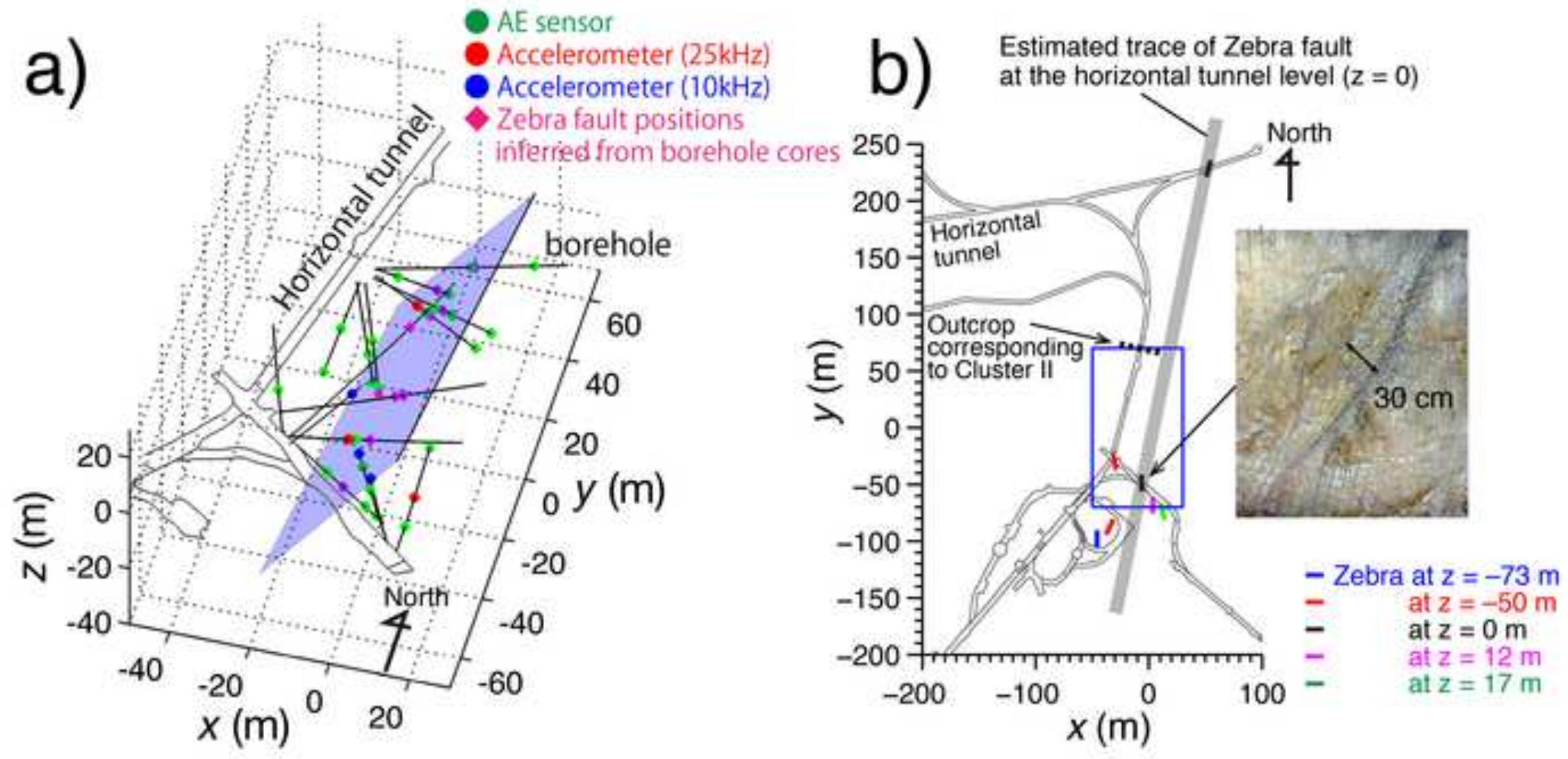




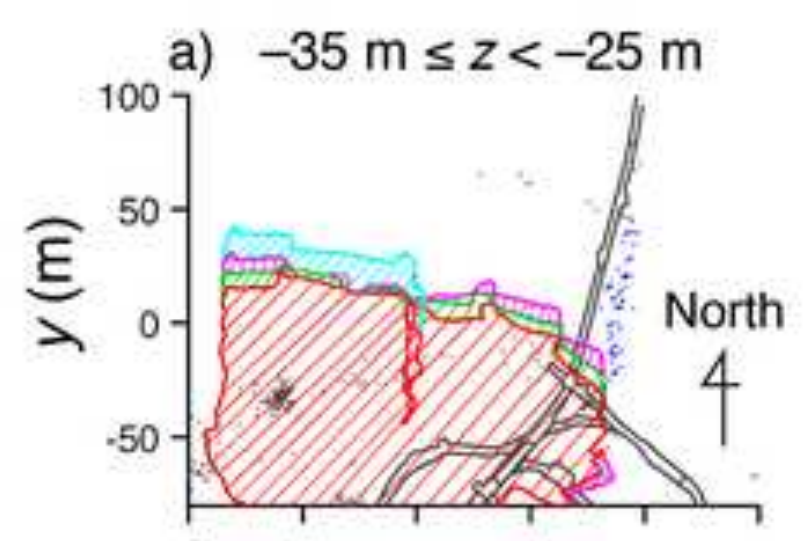

b) $-25 m \leq z<-15 m$

c) $-15 m \leq z<-5 m$
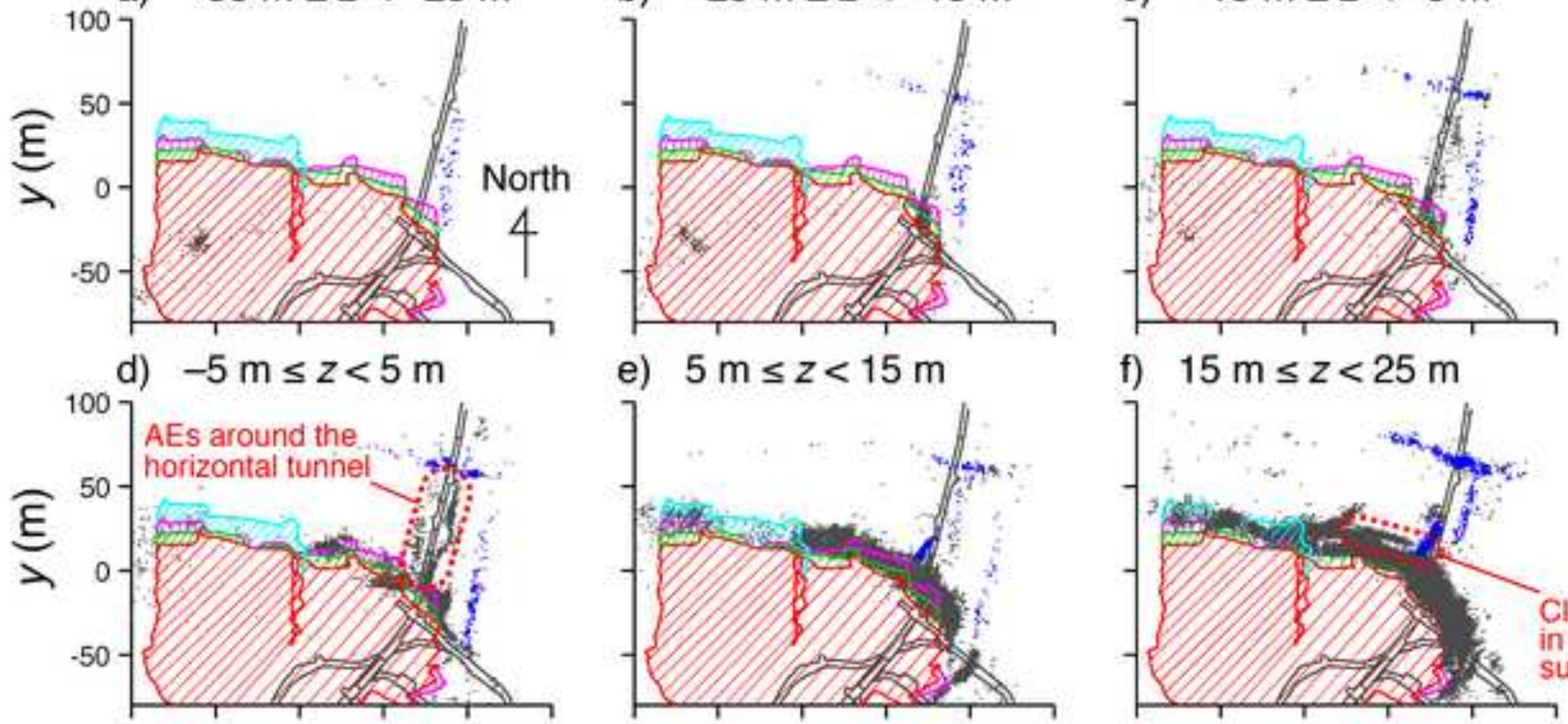

e) $5 \mathrm{~m} \leq z<15 \mathrm{~m}$

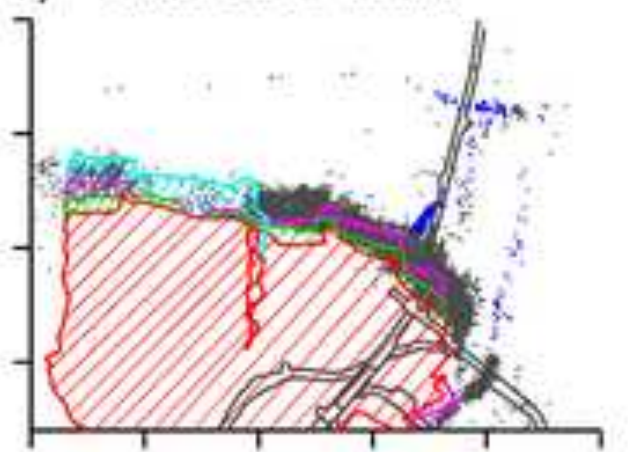

f) $15 \mathrm{~m} \leq z<25 \mathrm{~m}$
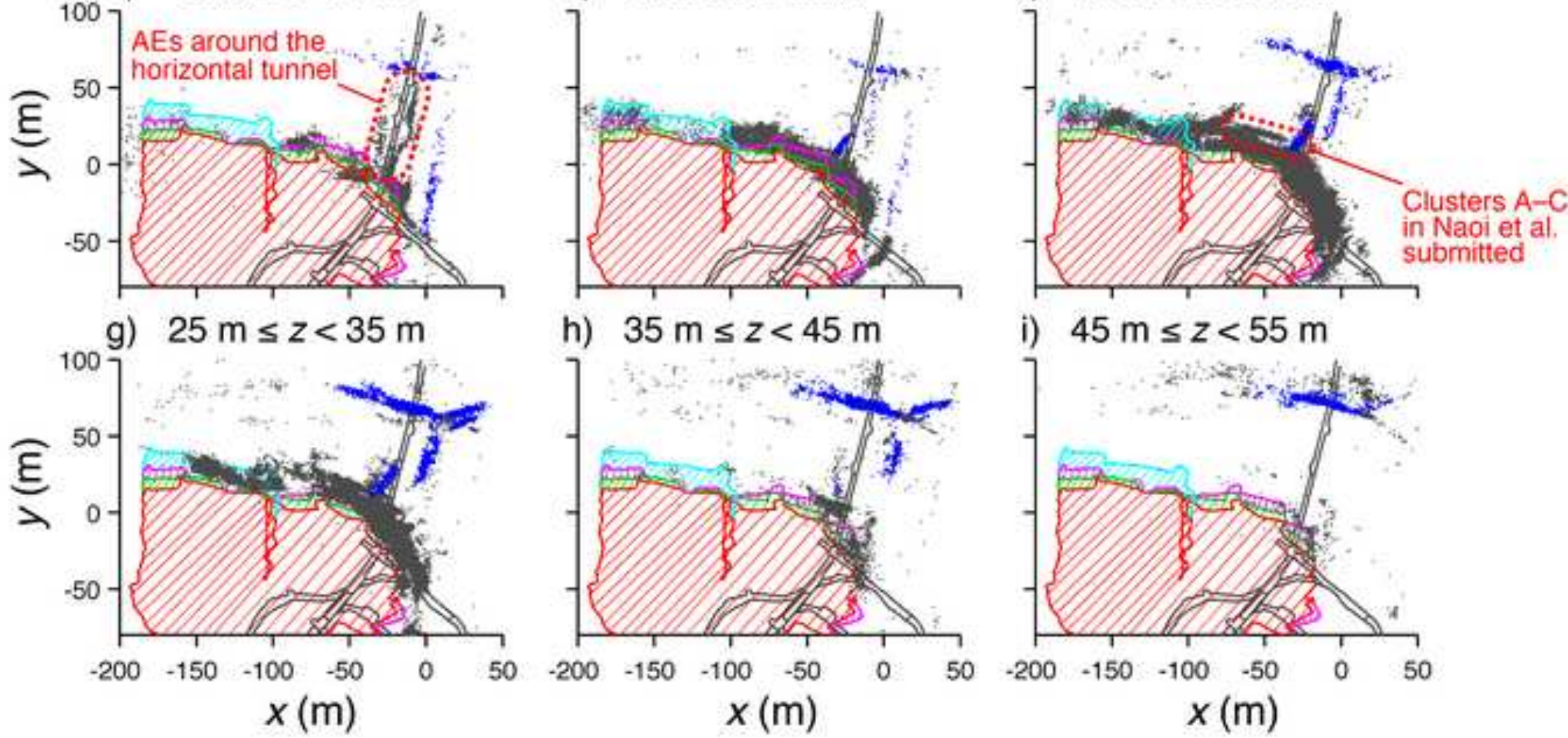

h) $35 \mathrm{~m} \leq z<45 \mathrm{~m}$

i) $45 \mathrm{~m} \leq z<55 \mathrm{~m}$
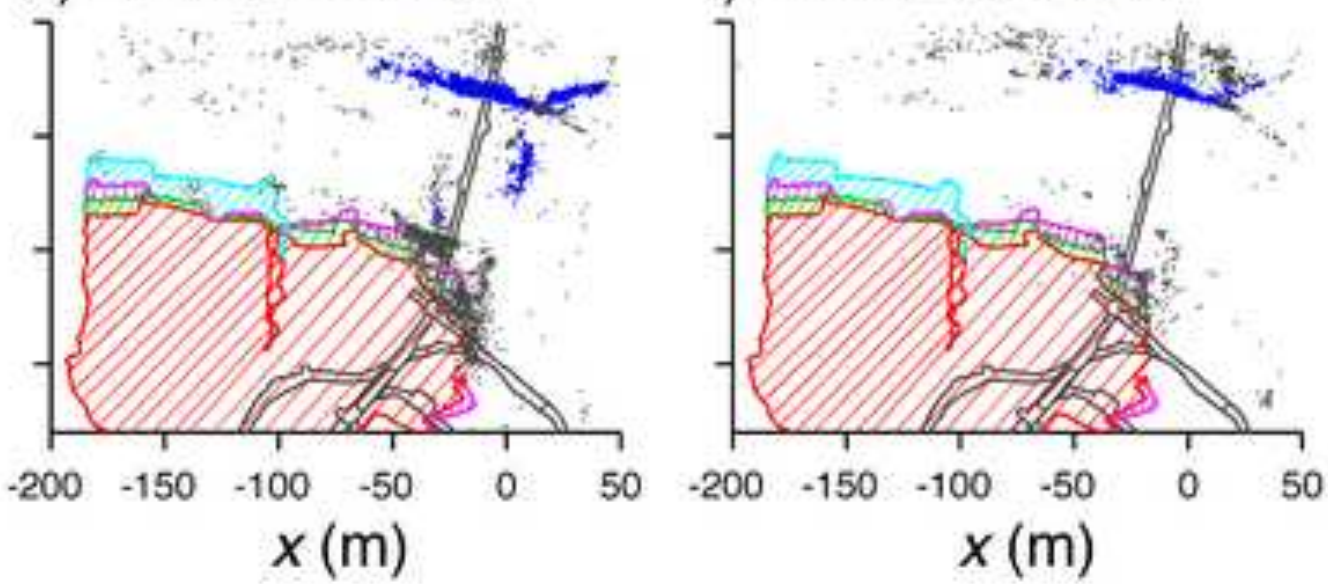

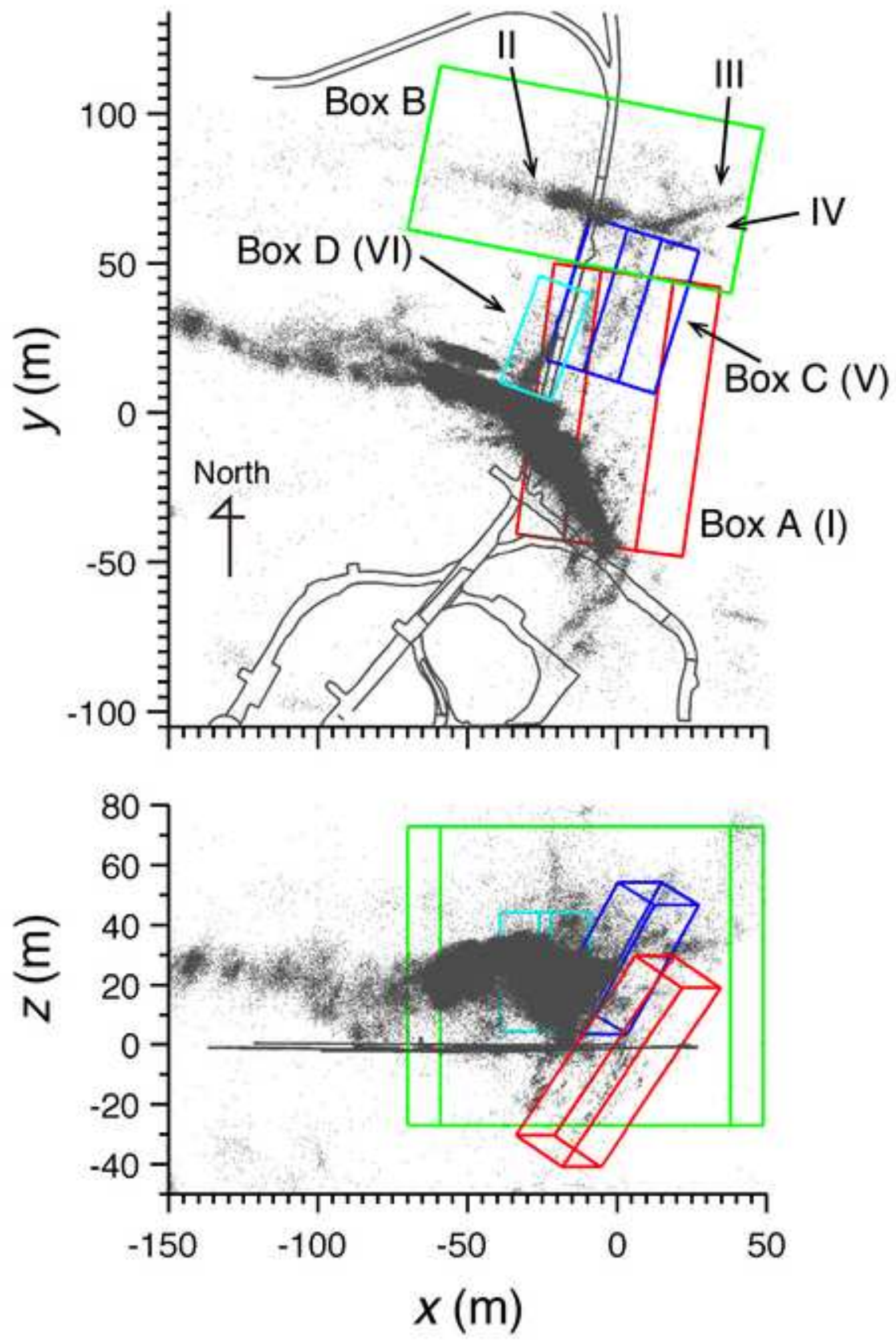


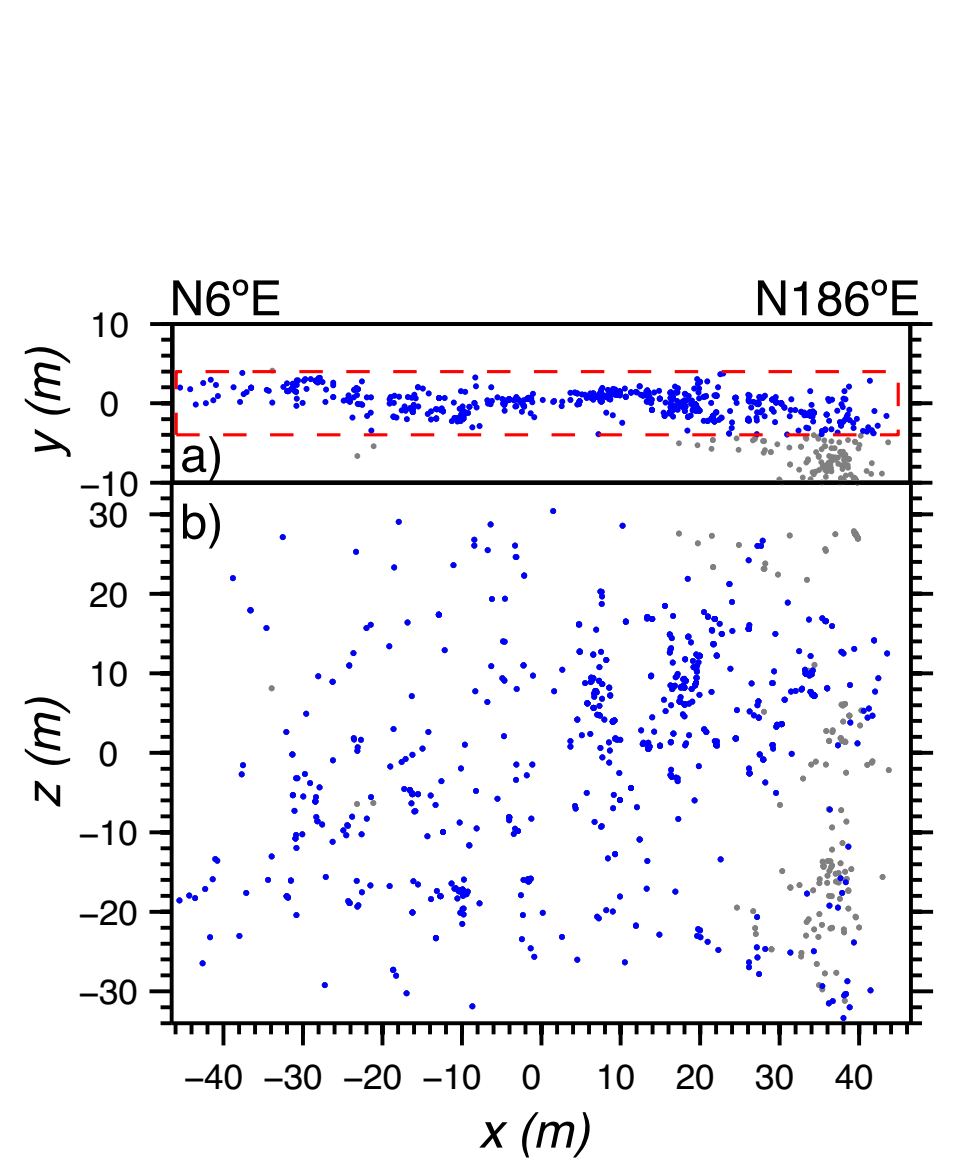

c) $\quad \mathrm{N} 6^{\circ} \mathrm{E}$

$\mathrm{N} 186^{\circ} \mathrm{E}$

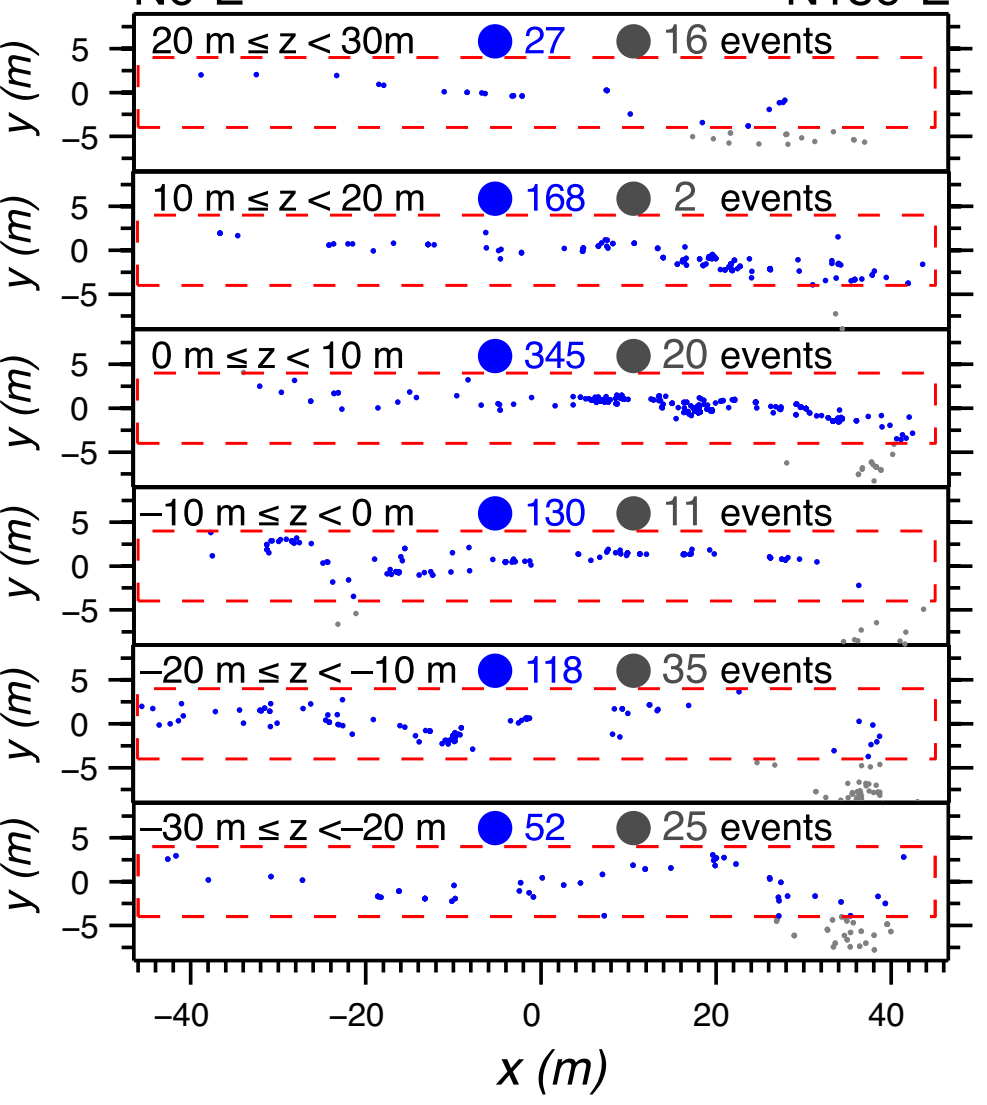



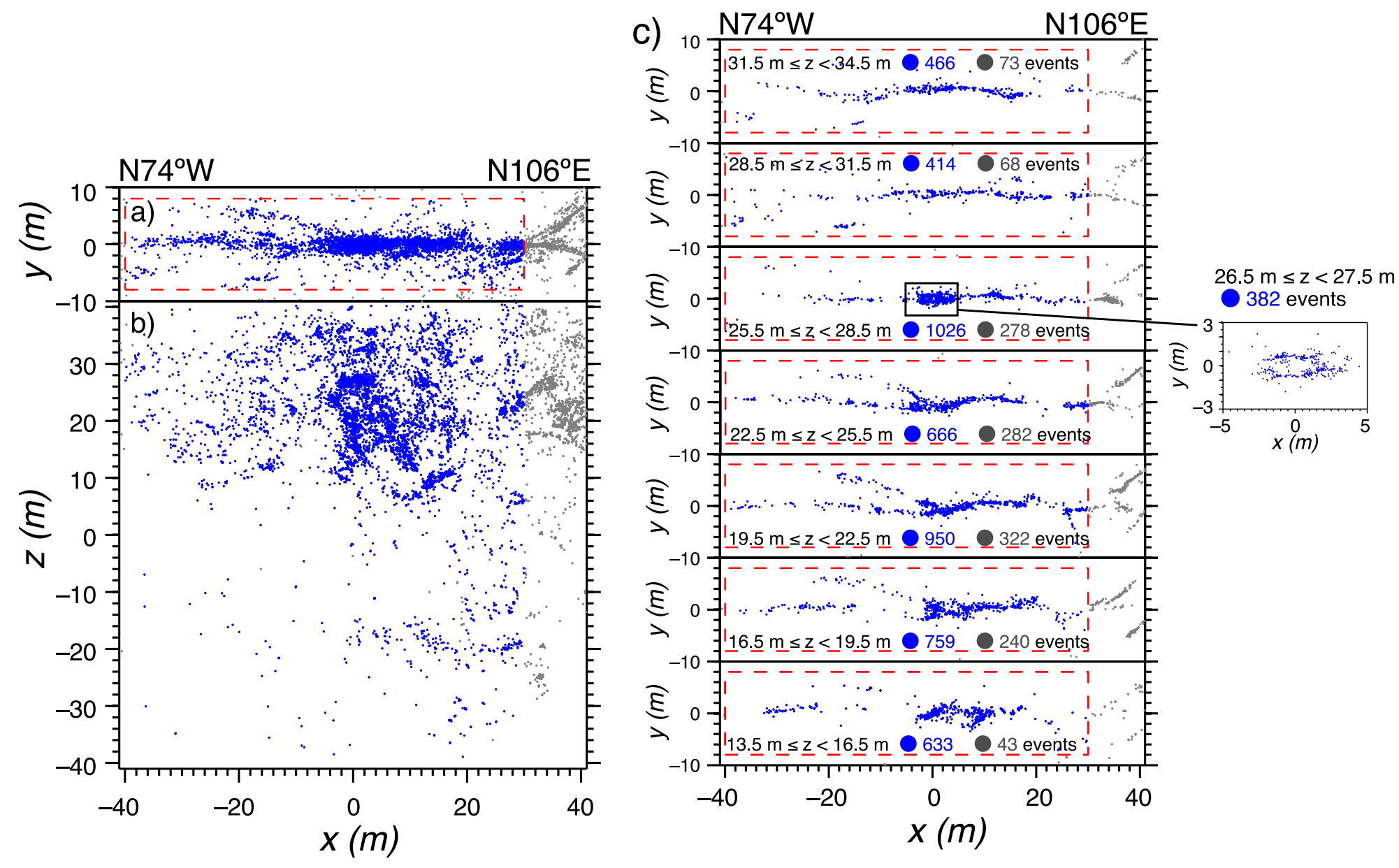

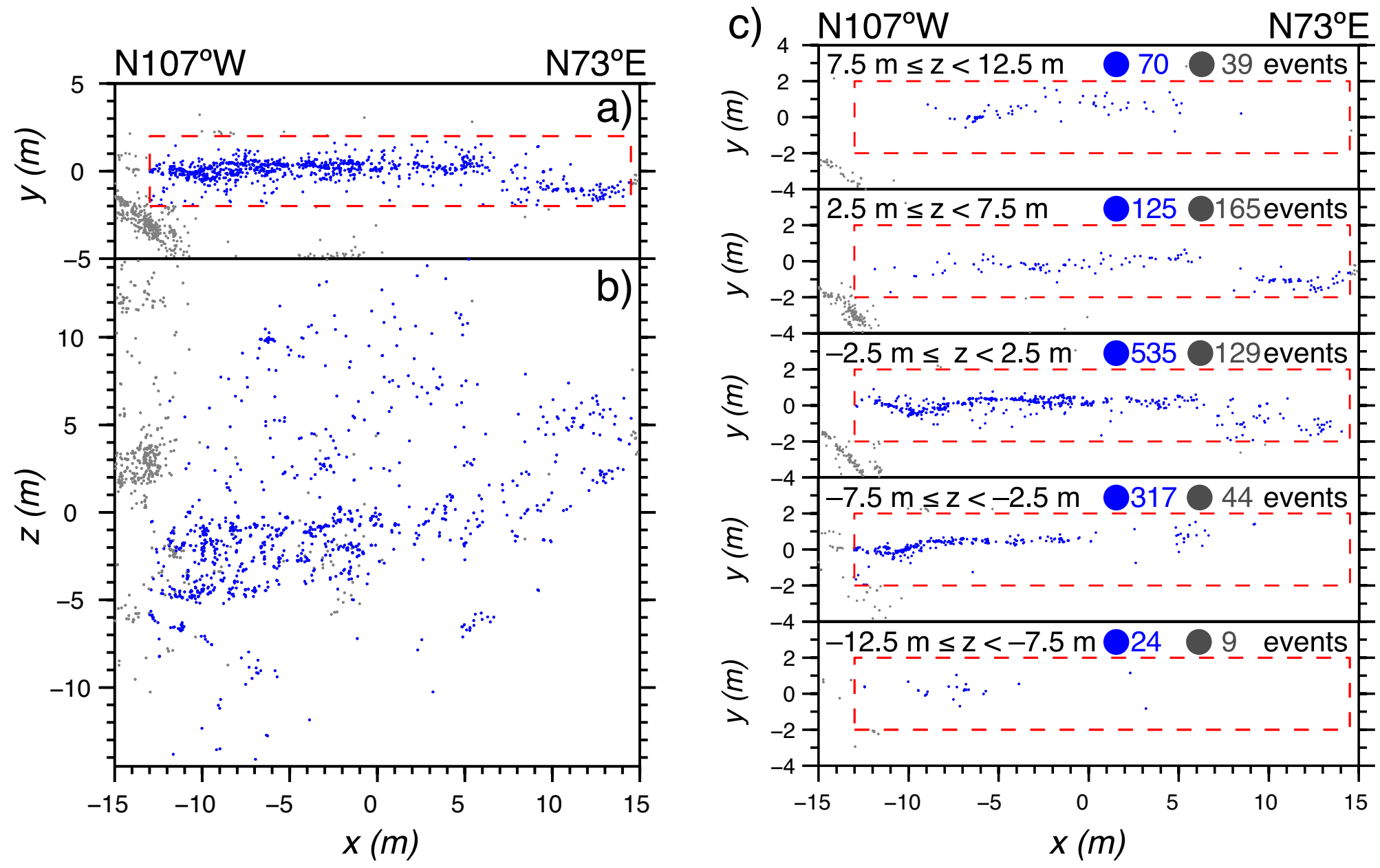


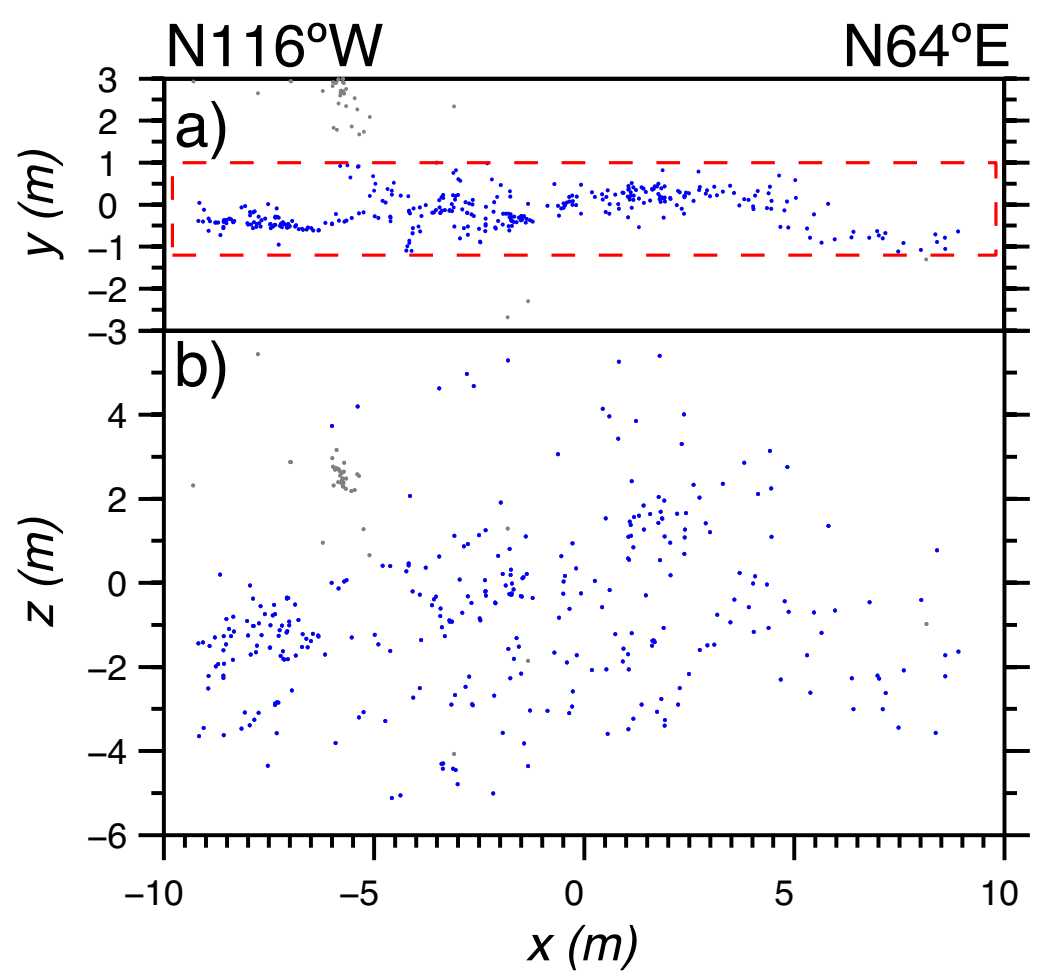

c) $\mathrm{N} 116^{\circ} \mathrm{W} \quad \mathrm{N} 64^{\circ} \mathrm{E}$
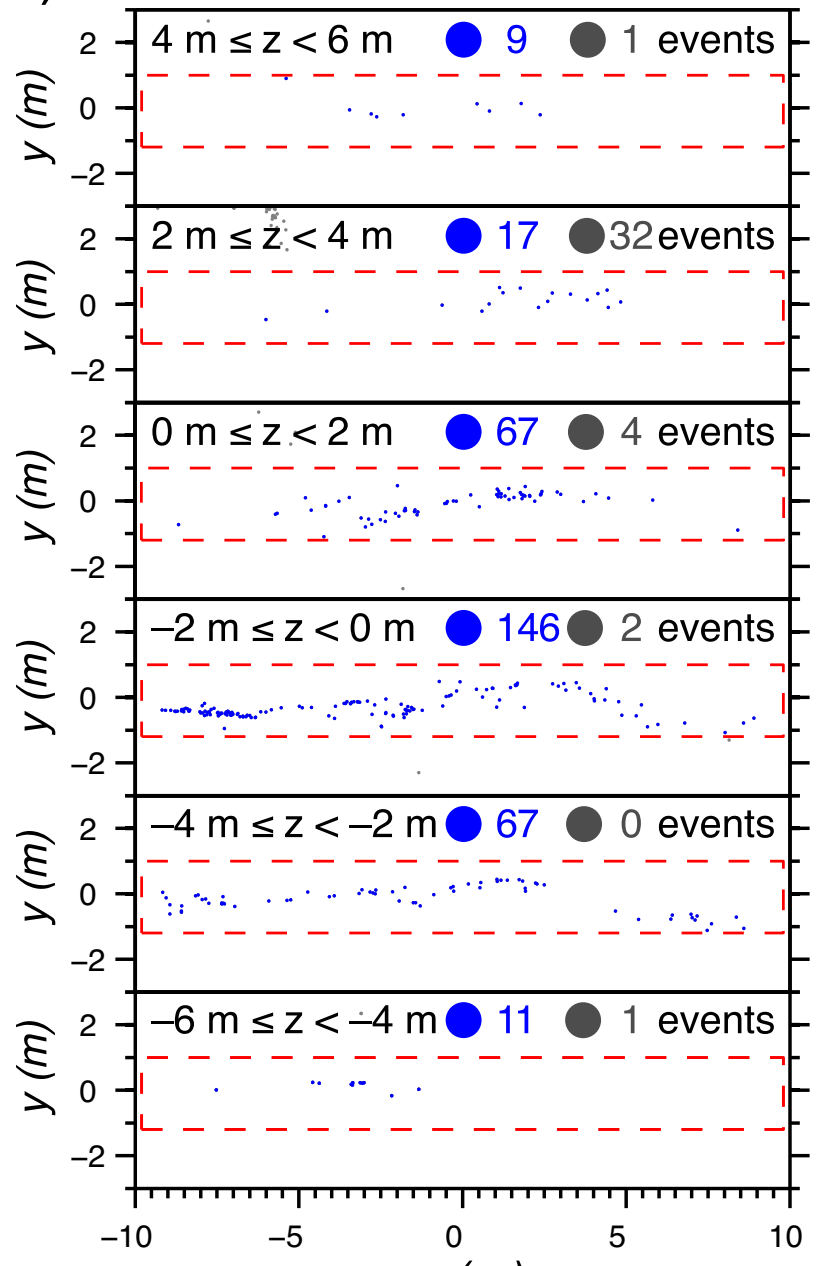

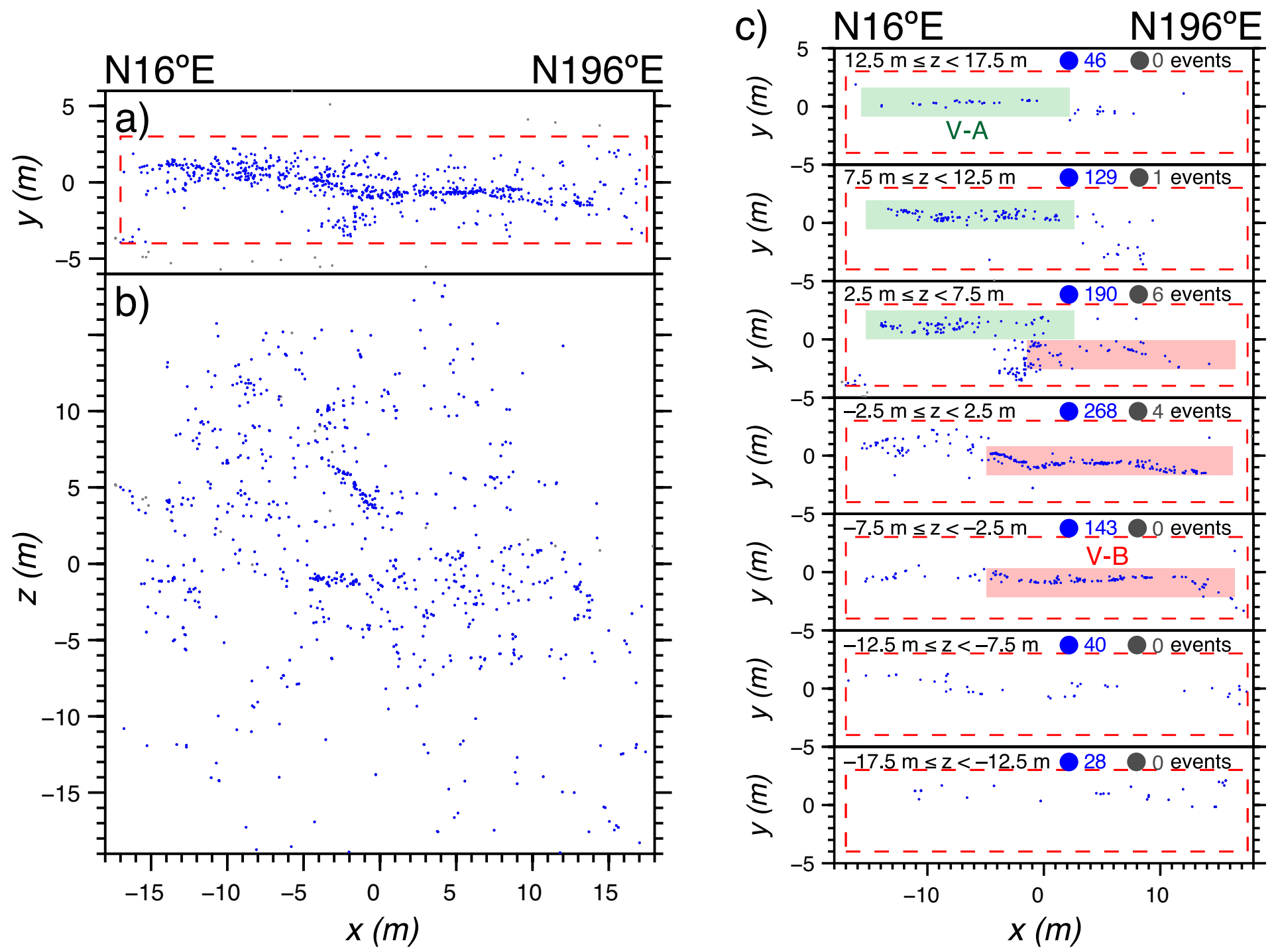


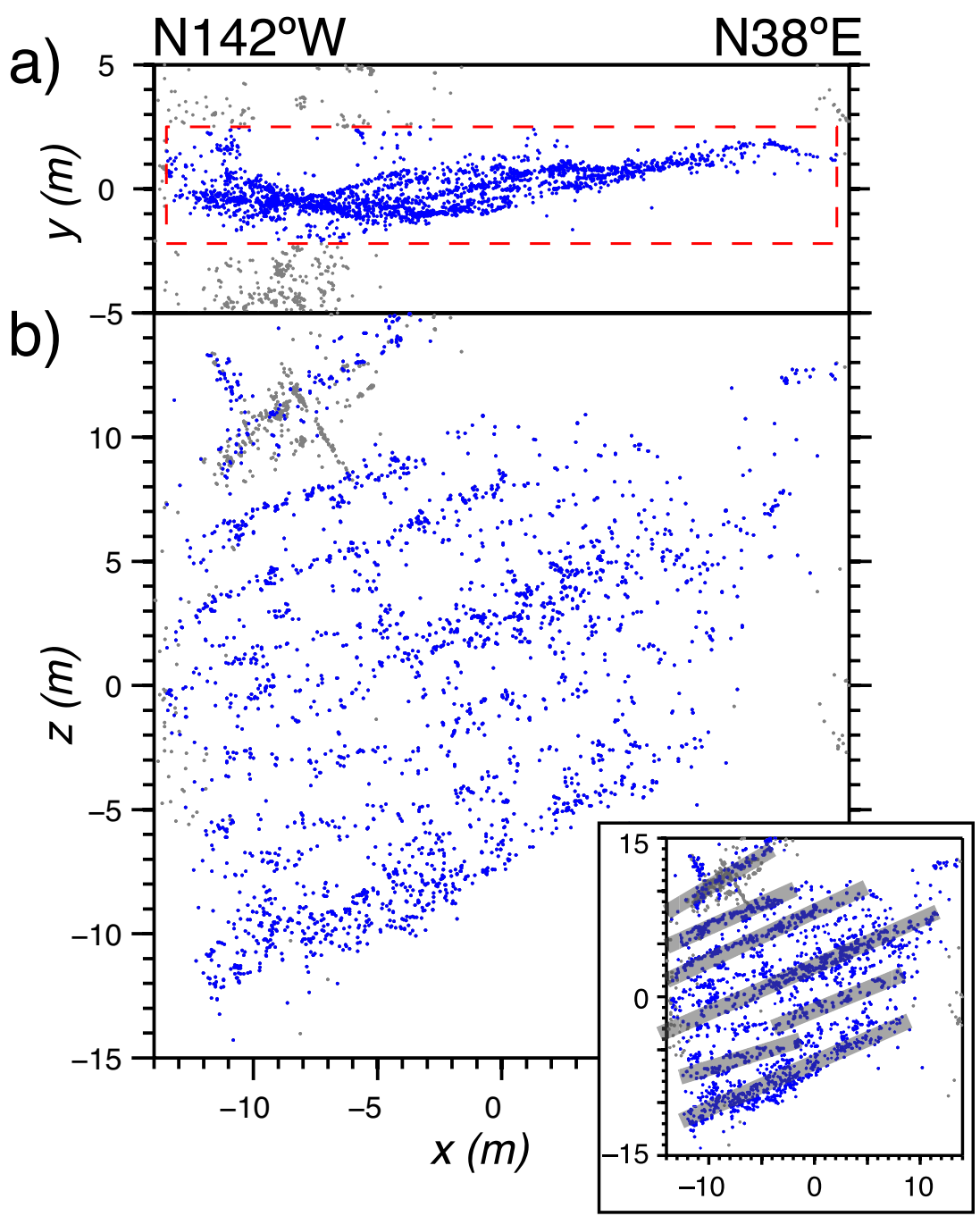

c)
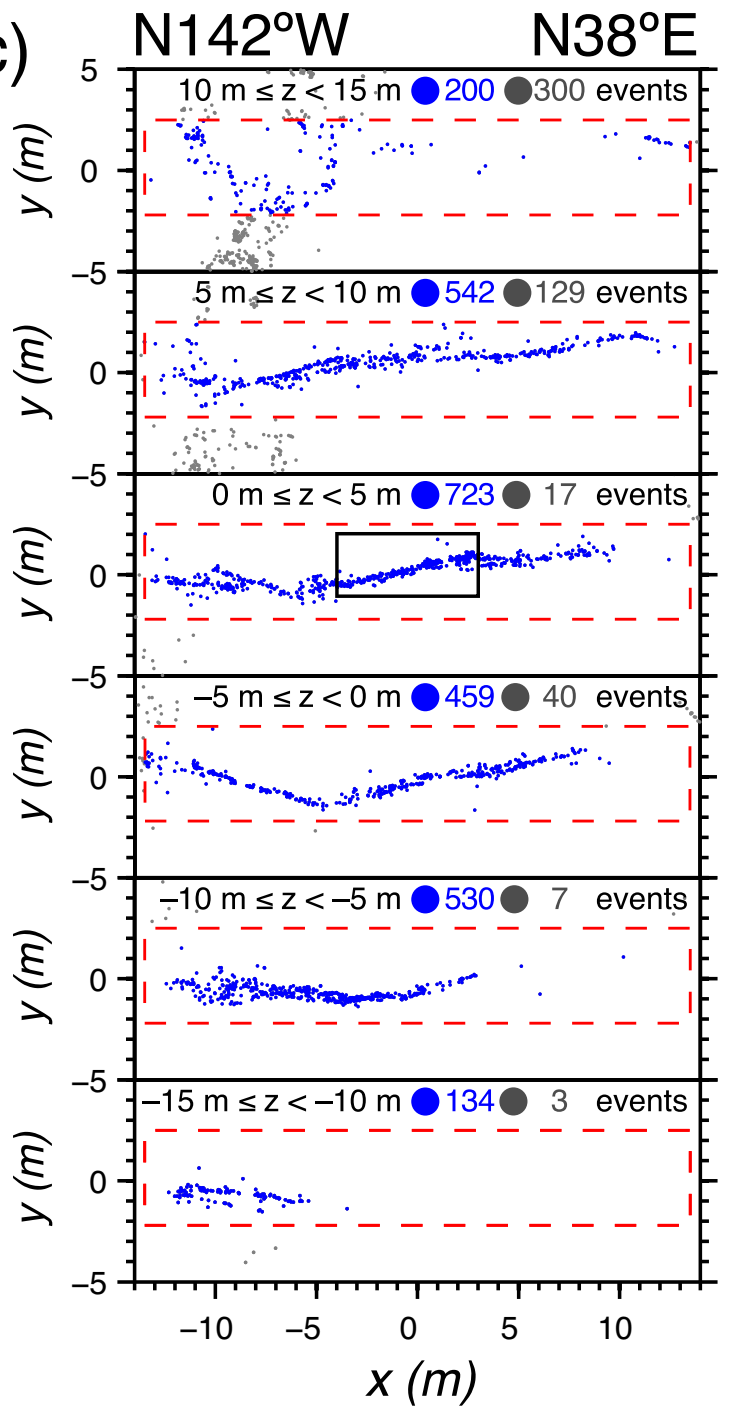
Figure 11

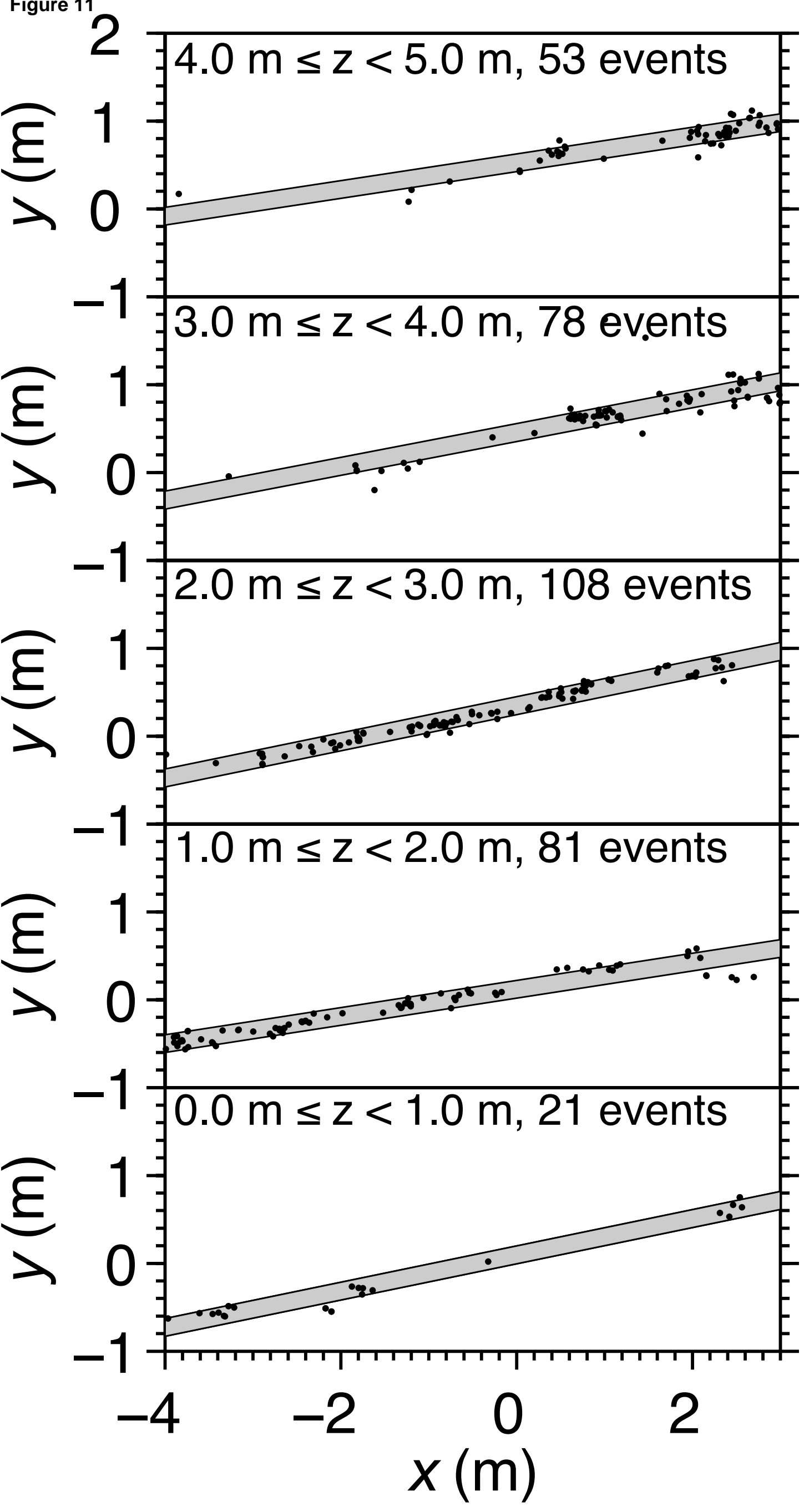

${ }^{\text {Figure }} 21$

$\underset{⿱ 乛}{\partial}$ 等 等

$\bar{E}$

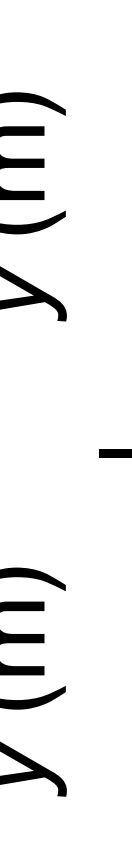
$-4$
$-2$
$x(\mathrm{~m})$

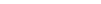

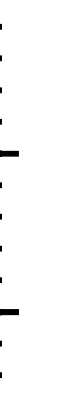
$E=$

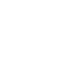

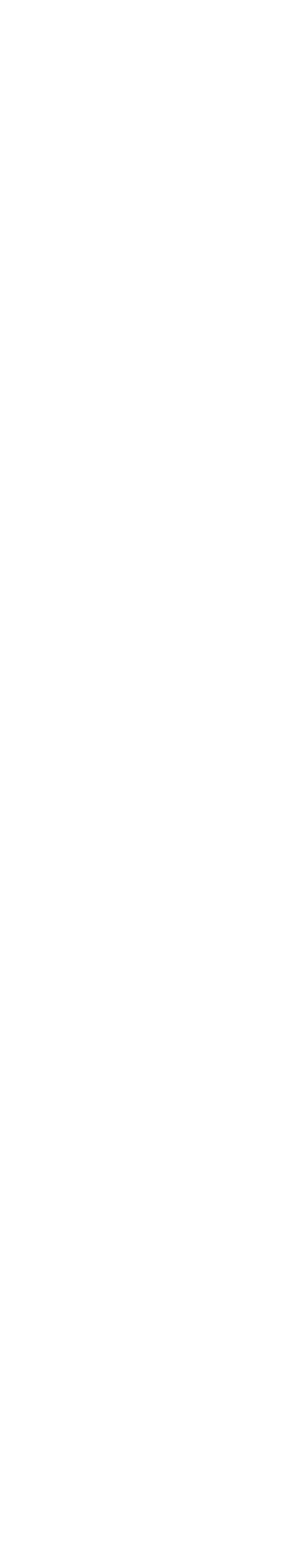


a)

Cluster I

$(13 \mathrm{~m} \leq x<23 \mathrm{~m})$

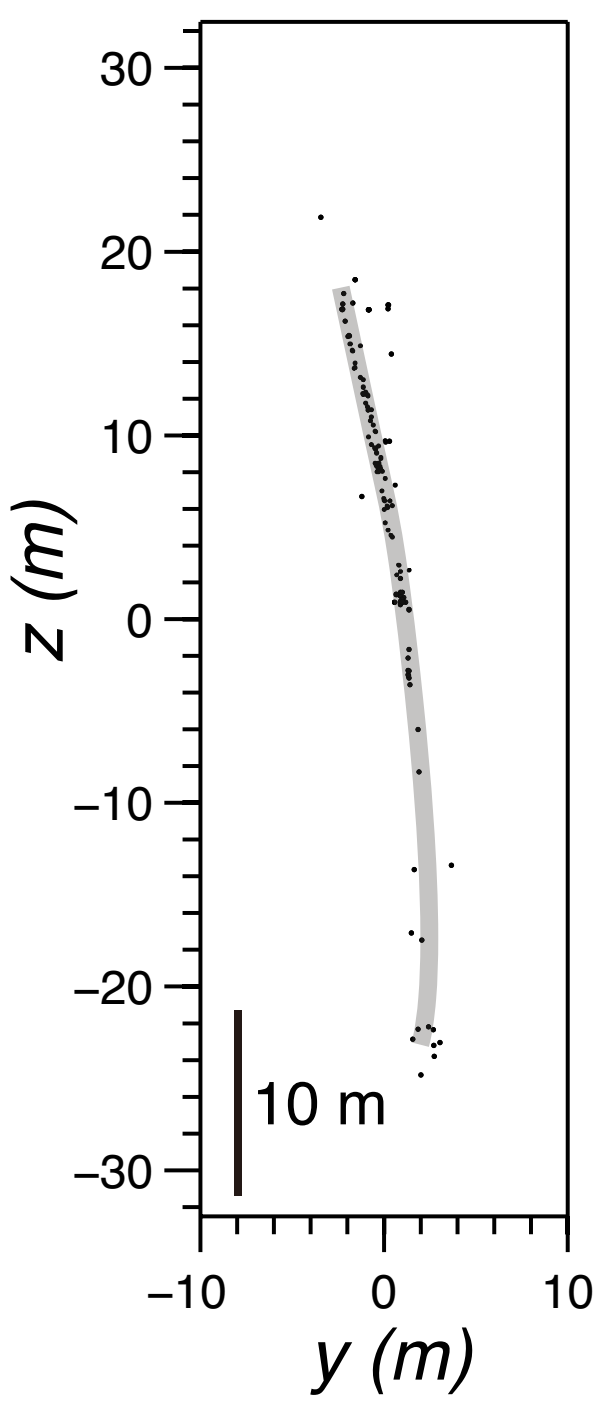

b)

Cluster II

$(-4 \mathrm{~m} \leq x<-1 \mathrm{~m})$

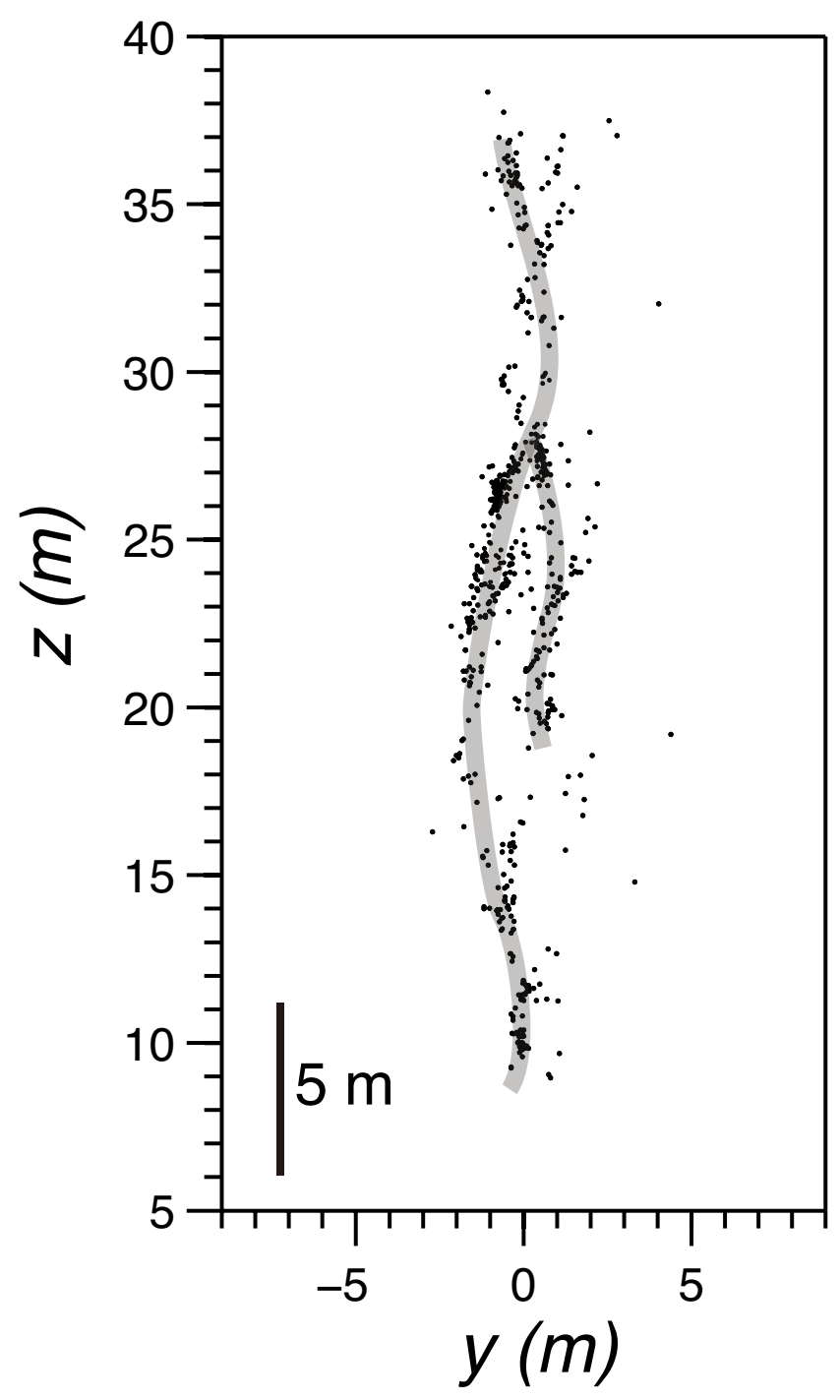

C) Cluster V $(-3 \mathrm{~m} \leq x<2 \mathrm{~m})$

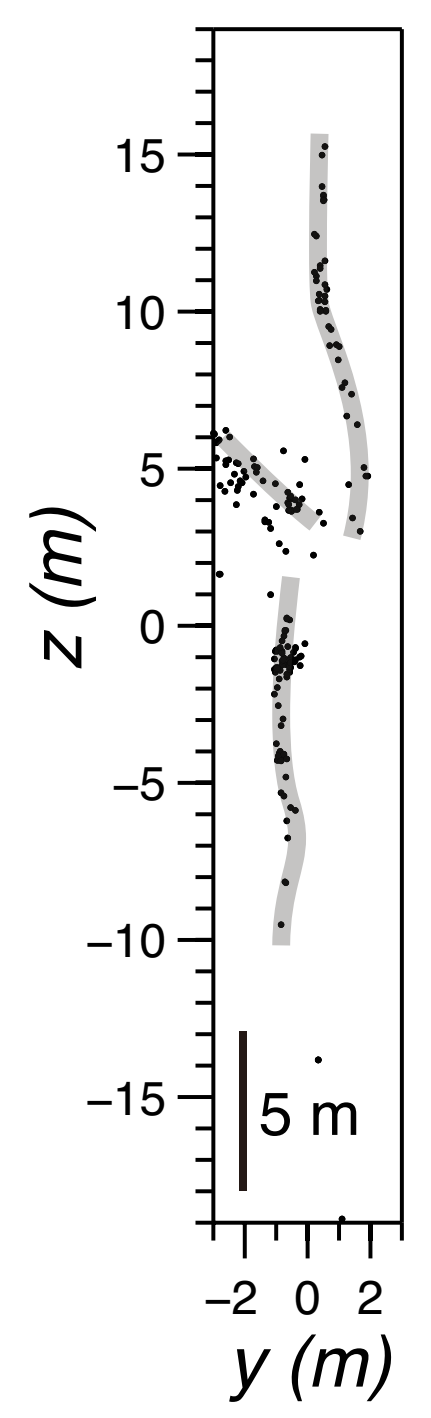


a)
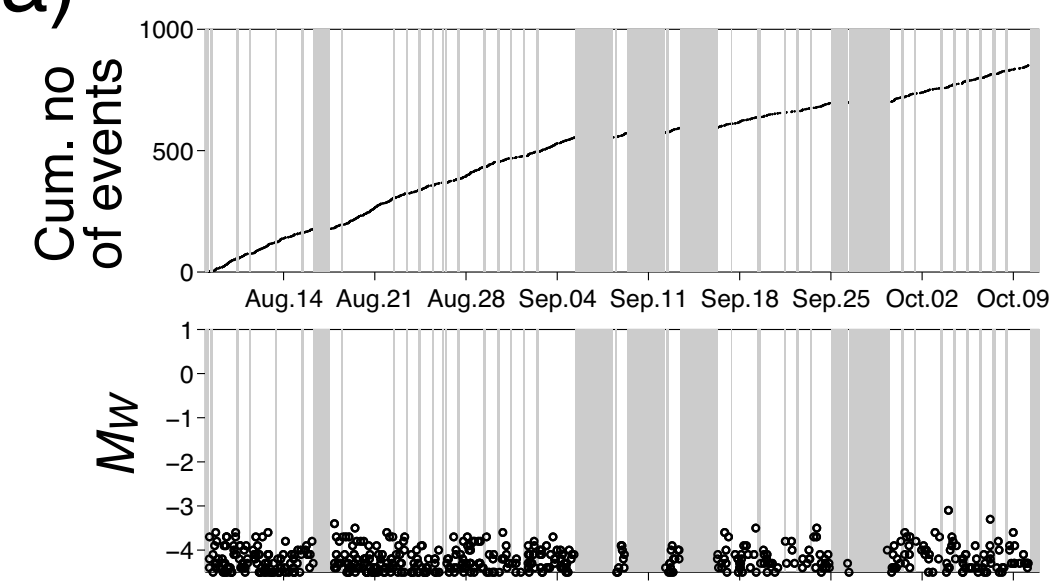

Aug.14 Aug.21 Aug.28 Sep.04 Sep.11 Sep.18 Sep.25 Oct.02 Oct.09

c)

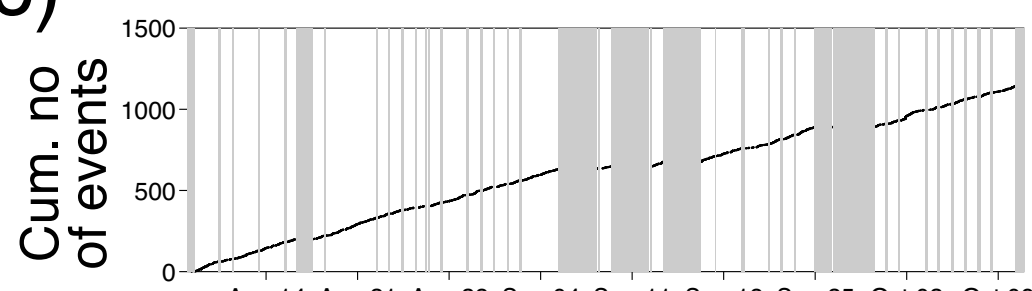

Aug.14 Aug.21 Aug.28 Sep.04 Sep.11 Sep.18 Sep.25 Oct.02 Oct.09

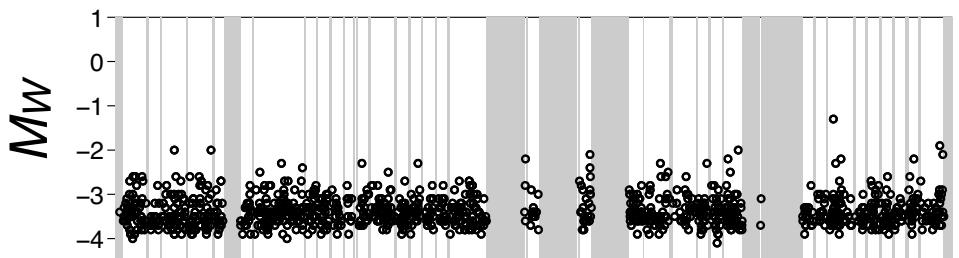

Aug.14 Aug.21 Aug.28 Sep.04 Sep.11 Sep.18 Sep.25 Oct.02 Oct.09

e)

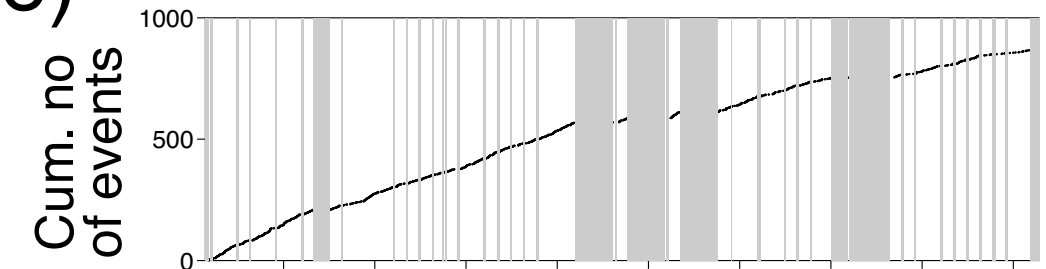

Aug.14 Aug.21 Aug.28 Sep.04 Sep.11 Sep.18 Sep.25 Oct.02 Oct.09

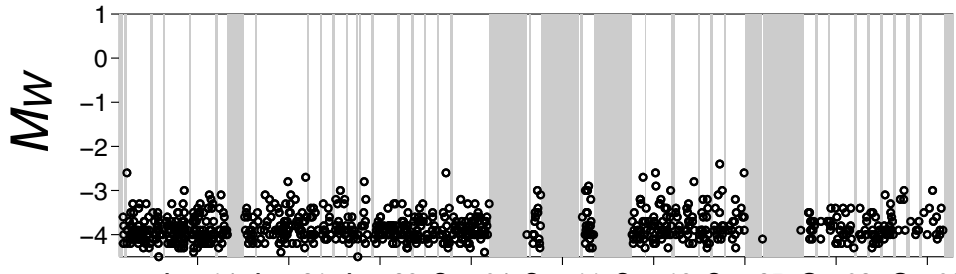

Aug.14 Aug.21 Aug.28 Sep.04 Sep.11 Sep.18 Sep.25 Oct.02 Oct.09 b)

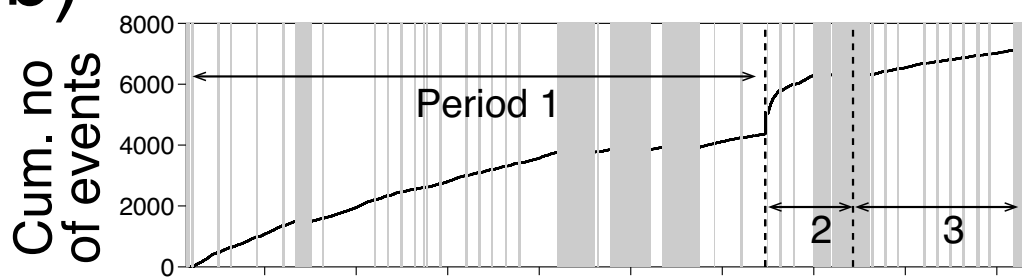

Aug.14 Aug.21 Aug.28 Sep.04 Sep.11 Sep.18 Sep.25 Oct.02 Oct.09

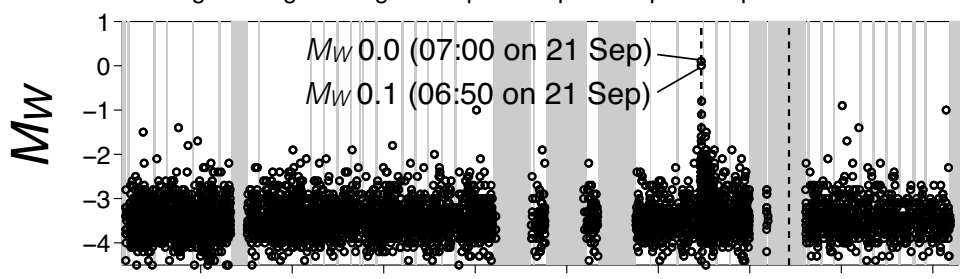

Aug.14 Aug.21 Aug.28 Sep.04 Sep.11 Sep.18 Sep.25 Oct.02 Oct.09

d)

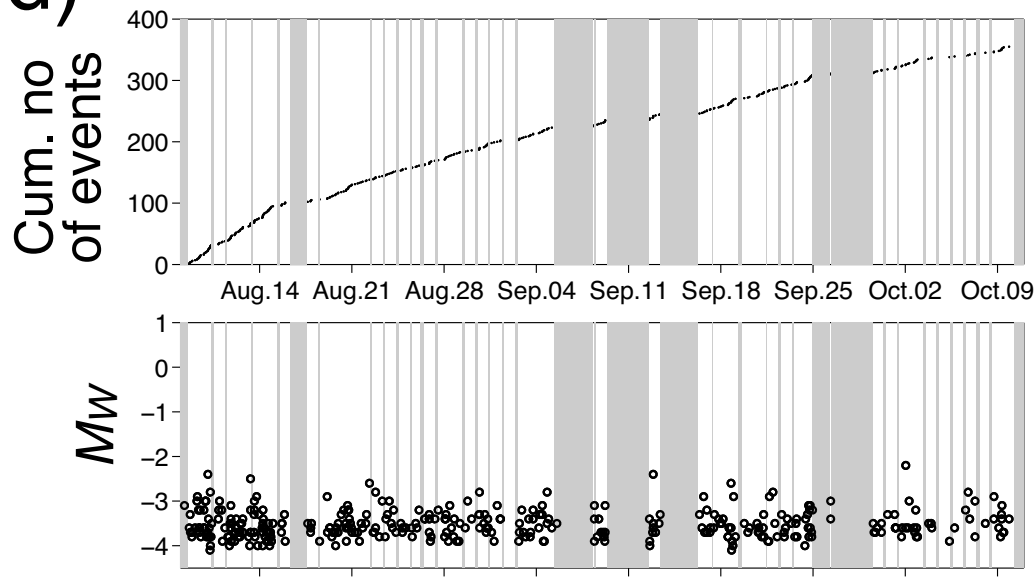

Aug.14 Aug.21 Aug.28 Sep.04 Sep.11 Sep.18 Sep.25 Oct.02 Oct.09

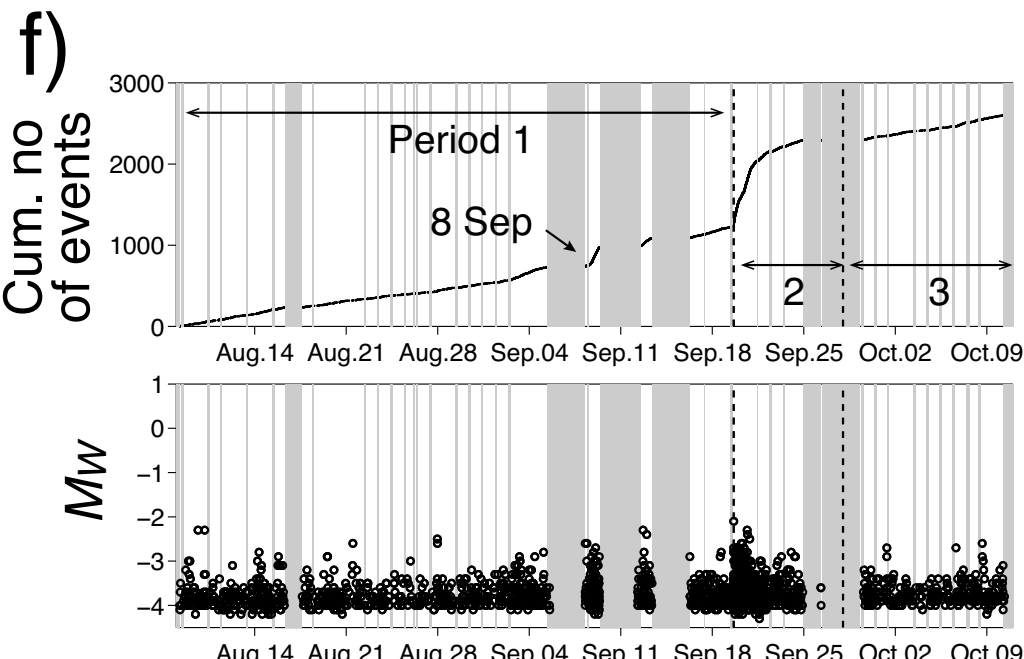
Aug.14 Aug.21 Aug.28 Sep.04 Sep.11 Sep.18 Sep.25 Oct.02 Oct.09 
a)

Cluster I b)

d

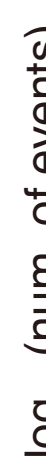

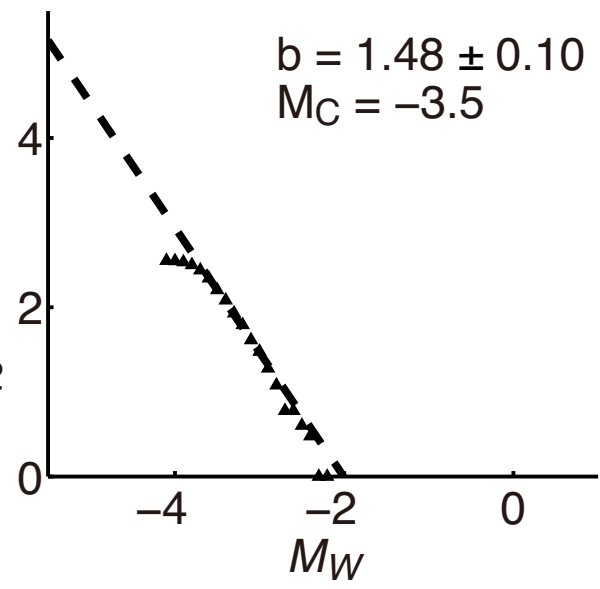

Cluster II

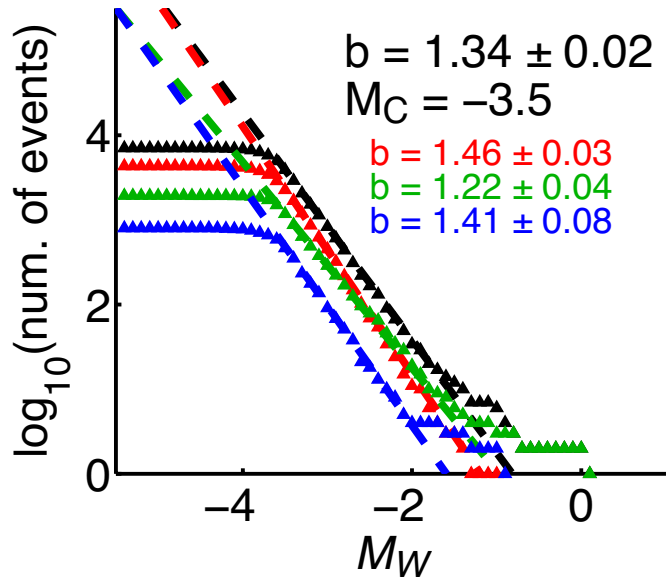

e)

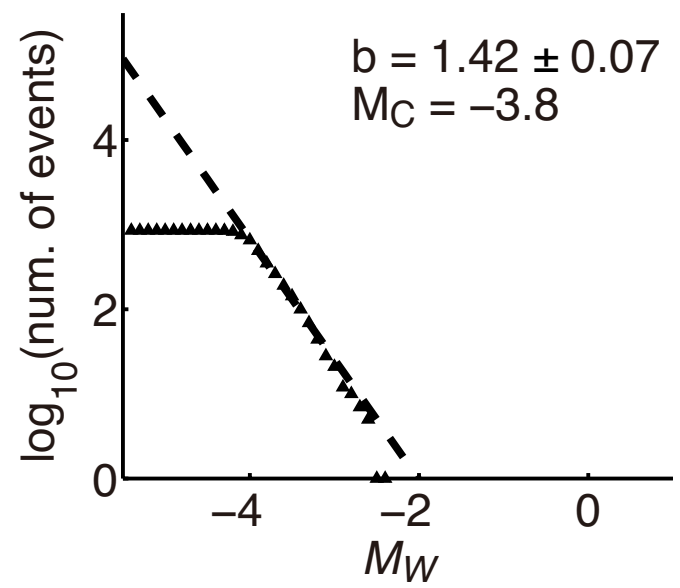

c)

Cluster III

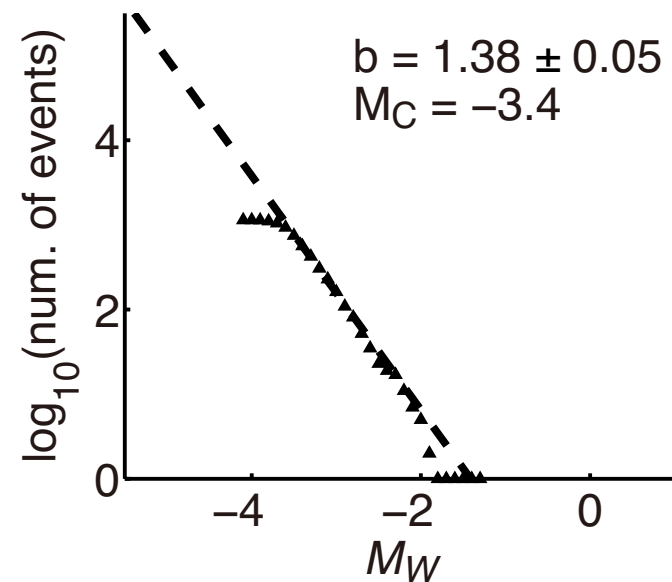

f)

Cluster VI

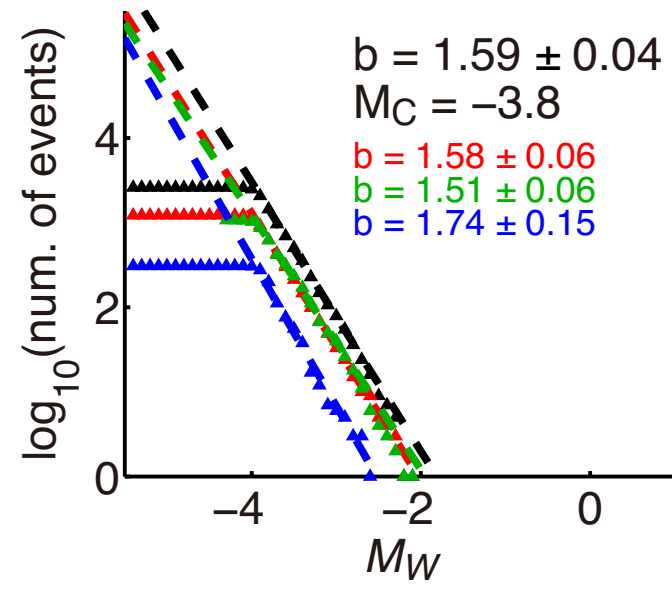

